\title{
TASK 23 - THERMODYNAMIC MODELING OF VOLATILE HAZARDOUS METAL BEHAVIOR IN THE VORTEC VITRIFICATION SYSTEM
}

Final Topical Report

Prepared for:

AAD Document Control

U.S. Department of Energy

National Energy Technology Laboratory

PO Box 10940, MS 921-143

Pittsburgh, PA 15236-0940

Cooperative Agreement No. DE-FC21-94MC31388--37

Performance Monitor: Donald Krastman

Prepared by:

Jan W. Nowok

John P. Hurley

Energy \& Environmental Research Center

University of North Dakota

PO Box 9018

Grand Forks, ND 58202-9018 


\section{DOE DISCLAIMER}

This report was prepared as an account of work sponsored by an agency of the United States Government. Neither the United States Government, nor any agency thereof, nor any of their employees makes any warranty, express or implied, or assumes any legal liability or responsibility for the accuracy, completeness, or usefulness of any information, apparatus, product, or process disclosed or represents that its use would not infringe privately owned rights. Reference herein to any specific commercial product, process, or service by trade name, trademark, manufacturer, or otherwise does not necessarily constitute or imply its endorsement, recommendation, or favoring by the United States Government or any agency thereof. The views and opinions of authors expressed herein do not necessarily state or reflect those of the United States Government or any agency thereof.

This report is available to the public from the National Technical Information Service, U.S. Department of Commerce, 5285 Port Royal Road, Springfield, VA 22161; phone orders accepted at (703) 487-4650.

\section{ACKNOWLEDGMENT}

This report was prepared with the support of the U.S. Department of Energy (DOE) National Energy Technology Laboratory Cooperative Agreement No. DE-FC21-94MC31388. However, any opinions, findings, conclusions, or recommendations expressed herein are those of the authors(s) and do not necessarily reflect the views of DOE.

\section{EERC DISCLAIMER}

LEGAL NOTICE This research report was prepared by the Energy \& Environmental Research Center (EERC), an agency of the University of North Dakota, as an account of work sponsored by DOE. Because of the research nature of the work performed, neither the EERC nor any of its employees makes any warranty, express or implied, or assumes any legal liability or responsibility for the accuracy, completeness, or usefulness of any information, apparatus, product, or process disclosed, or represents that its use would not infringe privately owned rights. Reference herein to any specific commercial product, process, or service by trade name, trademark, manufacturer, or otherwise does not necessarily constitute or imply its endorsement or recommendation by the EERC. 


\section{TABLE OF CONTENTS}

LIST OF FIGURES $\ldots \ldots \ldots \ldots \ldots \ldots \ldots \ldots \ldots \ldots \ldots \ldots \ldots \ldots \ldots$ ii

LIST OF TABLES $\ldots \ldots \ldots \ldots \ldots \ldots \ldots \ldots \ldots \ldots \ldots \ldots \ldots \ldots \ldots \ldots$ iii

EXECUTIVE SUMMARY $\ldots \ldots \ldots \ldots \ldots \ldots \ldots \ldots \ldots \ldots \ldots \ldots$ iv

$1.0 \quad$ INTRODUCTION $\ldots \ldots \ldots \ldots \ldots \ldots \ldots \ldots \ldots \ldots \ldots \ldots \ldots \ldots \ldots$

2.0 VAPORIZATION AND CONDENSATION BEHAVIOR OF ELEMENTS IN COMPLEX THERMAL SYSTEMS $\ldots \ldots \ldots \ldots \ldots \ldots \ldots \ldots \ldots 2$

3.0 THERMOCHEMICAL EQUILIBRIUM MODELING $\ldots \ldots \ldots \ldots \ldots \ldots \ldots \ldots$

4.0 NITROGEN, CHLORINE, FLUORINE, SULFUR, AND OH COMPONENT DISTRIBUTIONS IN THE FLAME $\ldots \ldots \ldots \ldots \ldots \ldots \ldots \ldots \ldots$

4.1 Nitrogen-Derived Components and CO Emission $\ldots \ldots \ldots \ldots \ldots \ldots \ldots$

4.2 Vapor Concentrations of Fluorine, Chlorine, Hydroxyl, and Sulfur Species _. . . 8

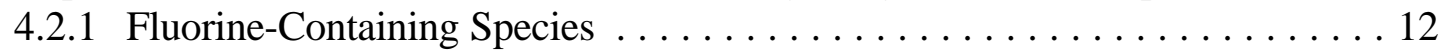

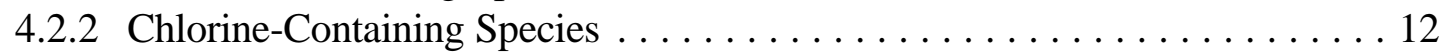

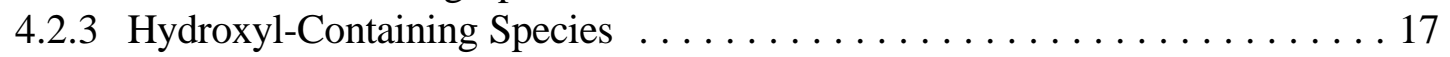

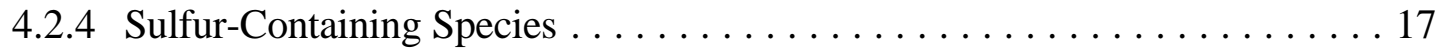

5.0 DISTRIBUTION OF RADIONUCLIDES IN THE EXHAUST GAS AND MELT . . . 17

5.1 Remarks about Calculations of Radionuclide Immobilization and Vaporization . . 17

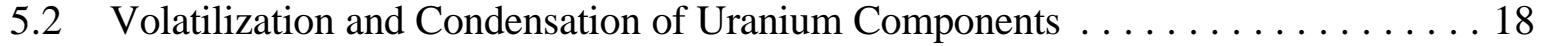

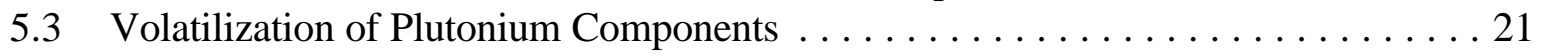

5.4 Volatilization of Thorium and Neptunium Components . . . . . . . . . . . . 24

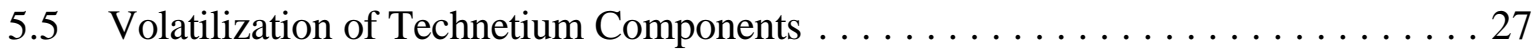

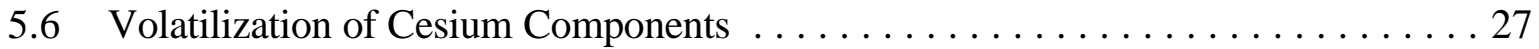

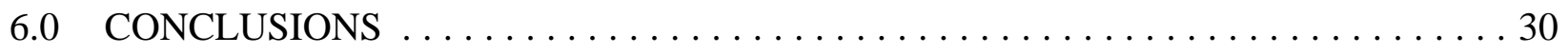

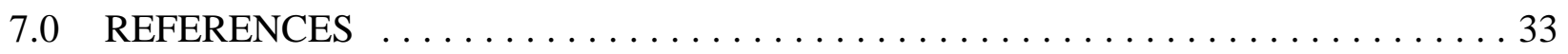




\section{LIST OF FIGURES}

1 Concentrations of elemental oxides in coal ash deposits formed in a utility boiler as compared to the temperature of the deposit $\ldots \ldots \ldots \ldots \ldots \ldots \ldots \ldots \ldots \ldots$

2 Concentrations of nitrogen-derived components in combusted propane as a function of oxygen-to-propane ratio and temperature $\ldots \ldots \ldots \ldots \ldots \ldots \ldots \ldots \ldots \ldots$

3 Concentration of $\mathrm{CO}$ in combusted propane as function of oxygen-to-propane ratio and

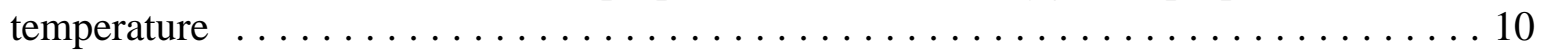

4 The standard enthalpy change for all possible reactions in the propane-air flame as a function of oxygen-to-propane ratio and temperature $\ldots \ldots \ldots \ldots \ldots \ldots \ldots \ldots$

5 Composition distribution of $\mathrm{F}, \mathrm{Cl}, \mathrm{OH}$, and $\mathrm{S}$ components in the vapor phase $\ldots \ldots \ldots 11$

6 Composition distribution of major fluorides in the vapor phase $\ldots \ldots \ldots \ldots \ldots \ldots$

7 Composition distribution of major chlorides in the vapor phase $\ldots \ldots \ldots \ldots \ldots \ldots$

8 Composition distribution of major hydroxides in the vapor phase $\ldots \ldots \ldots \ldots \ldots 15$

9 Composition distribution of major sulfides and sulfates in the vapor phase. $\ldots \ldots \ldots 16$

10 Distribution of uranium-derived components in the vapor phase as functions of flame

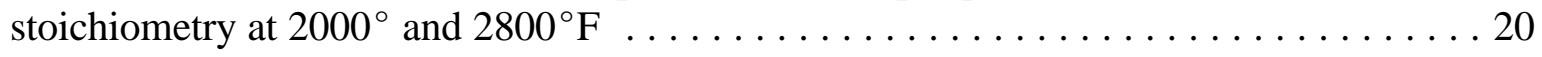

11 Effect of temperature and flame stoichiometry on uranium vaporization $\ldots \ldots \ldots \ldots 22$

12 Concentrations of different vapor-phase plutonium species as functions of flame

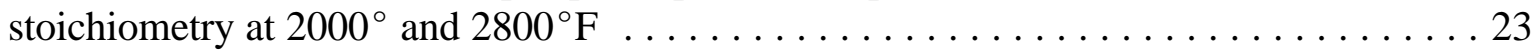

13 Percentage of plutonium in the vapor phase as functions of flame stoichiometry and

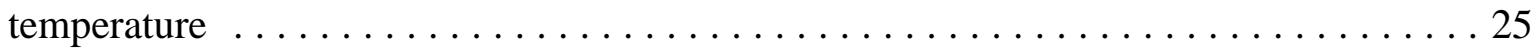

14 Percentage of $\mathrm{Pu}$ in the vapor and solid phases at $2800^{\circ} \mathrm{F}$ as functions of the concentration of plutonium in the waste material and the flame stoichiometry ............. 25

15 Mole percentage of thorium that vaporizes at equilibrium as functions of flame

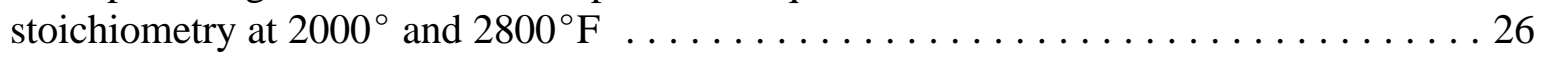

16 Concentrations of different vapor-phase thorium species as functions of flame stoichiometry

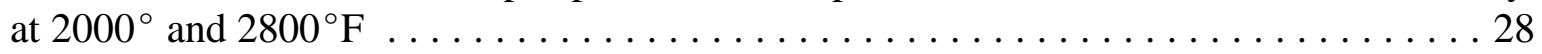

Continued ... 


\section{LIST OF FIGURES (continued)}

17 Concentrations of different vapor-phase technetium species as functions of flame

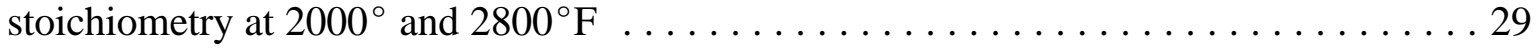

18 Concentrations of different vapor-phase cesium species as functions of temperature for oxygen to propane ratios of 4.00 (reducing) and 5.44 (oxidizing) $\ldots \ldots \ldots \ldots$

19 Condensation temperature of $\mathrm{Cs}_{2} \mathrm{CrO}_{4}$ liquid as a function of temperature and concentration for reducing and oxidizing conditions $\ldots \ldots \ldots \ldots \ldots \ldots \ldots \ldots \ldots \ldots \ldots \ldots \ldots \ldots \ldots \ldots$

\section{LIST OF TABLES}

1 Constituents in RCRA Stream Used for Thermodynamic Calculations $\ldots \ldots \ldots \ldots$

2 Radionuclide Concentrations Used for Thermodynamic Calculations $\ldots \ldots \ldots \ldots$

3 Thermodynamic Calculations for Propane-Air Mixtures $\ldots \ldots \ldots \ldots \ldots$

4 Radionuclide Compounds in the FACT Database . . . . . . . . . . . . . . . . . 19 


\section{TASK 23 - THERMODYNAMIC MODELING OF VOLATILE HAZARDOUS METAL BEHAVIOR IN THE VORTEC VITRIFICATION SYSTEM}

\section{EXECUTIVE SUMMARY}

Experience at the University of North Dakota Energy \& Environmental Research Center (EERC) with low-grade fuel-fired thermal energy systems has shown that portions of the inorganic material inherent in the fuel vaporize during heating. Vaporization can occur either through physical vaporization or through chemical reactions, especially in the presence of sulfur, halides, or water vapor. It is likely that in a waste melter, vaporization also occurs, not just from a solid or liquid fuel, but from the wastes themselves. Downstream of a melter, the vapor species can condense, possibly forming fine particulates or even massive deposits that are highly concentrated in specific elements. In proprietary EERC work, element enrichment factors of up to 50,000 times have been measured in massive coal ash deposits as compared to the fuel. Such enrichments of radioactive or Resource Conservation and Recovery Act (RCRA) elements in a melter could produce hazardous deposits at specific sites within the system. Submicron particulates may pass through the scrubber and could more rapidly clog downstream highefficiency particulate air (HEPA) filters. However, knowledge of the vaporization and condensation behavior of the hazardous elements can be used to propose simple methods to prevent such problems from occurring.

The primary activity of Task 23 is to perform thermochemical equilibrium computer modeling to provide a background of information on the possible vaporization and condensation behavior of radionuclides and RCRA elements in a propane-air flame. Two temperatures in or near the flame were modeled, $2000^{\circ}$ and $2800^{\circ} \mathrm{F}$, in a broad range of oxygen-propane ratios (1.5-7.0). The work is being done in cooperation with the Vortec Corporation of Collegeville, Pennsylvania. Vortec is building a demonstration fossil energy-fired vitrification system at the Paducah Gaseous Diffusion Plant near Paducah, Kentucky.

The goal of the activity is to use the results of the computer modeling to help predict the potential for operational difficulties in gas-fired waste melters. By modeling the vaporization/condensation behavior of hazardous metals within the melter, we can determine and quantify factors affecting the development of some of these operational issues. Once this information is obtained, simple methods to prevent their occurrence can be delineated. This may include on-line control with sootblowers, installation of access panels at specific locations to allow hot off-line deposit removal, or minimizing vaporization by appropriate selection of feedstocks or blending scenarios or operating the burner in fuel-rich or lean-modes.

Version 3.0 of the Facility for the Analysis of Chemical Thermodynamics, or FACT code, was used for the modeling. It was developed at the Ecole Polytechnique de Montréal. The advantage of the FACT model over other codes is the amount of species in the thermochemical database (over 7000), the number of elements and species that can participate in complex reactions, and the ability to optimize solutions representing nonideal mixing in complex melts. 
For modeling in the Vortec melter system, the FACT modeling program is being used to evaluate the partial pressures of major components in a flame derived from $\mathrm{CN}, \mathrm{F}, \mathrm{Cl}, \mathrm{S}, \mathrm{OH}, \mathrm{U}$, $\mathrm{Pu}, \mathrm{Th}, \mathrm{Np}, \mathrm{Tc}$, and $\mathrm{Cs}$. The maximum concentrations expected in the possible waste materials to be vitrified by Vortec during a 30-day test period early in the operation of the system were used for the calculations. In the flame, stable equilibria are seldom reached; however, an equilibrium analysis can give insight into possible chemical reactions that may occur under given conditions of composition, temperature, and pressure. It was assumed that the vapor-phase products formed at high temperatures are transported by the flue gas to lower temperatures where they can condense. It is important to realize, however, that uncertainties will occur in the prediction of vaporization and condensation behavior if components that may form during operation of the Vortec system are not included in the FACT code database because of lack of thermodynamic data. The calculations were performed in a series of steps in order to diminish the effect of competing system conditions.

\section{URANIUM}

The calculations indicate that at the maximum uranium concentration expected in the Vortec feed, up to $4 \%$ of the uranium could exist as vapor in a stoichiometric flame at equilibrium and up to $7 \%$ in fuel-lean conditions. The primary uranium vapor species are oxides and oxyfluorides. Uranium chloride vapors are predicted to be present at much lower concentrations, indicating that chlorine does not play a significant role in vaporizing the uranium. The majority of the vapor uranium is $\mathrm{UO}_{3}$, followed by $\mathrm{UO}_{2} \mathrm{~F}$, indicating that small changes in fluorine contents in the feed material will not dramatically affect the amount of uranium vaporization, but large increases could increase vaporization. Over $99 \%$ of the vaporized uranium can be expected to condense by the time the gas cools to $2000^{\circ} \mathrm{F}$. This implies that the system design should provide for removing deposits formed between the flame and the point in the system where the gas reaches this temperature. In particular, the design should allow for knocking deposits off walls or heat exchange surfaces such that the deposit falls into the melt material. Once in the melt, the larger deposit pieces would be slow to vaporize and could be removed from the system with the glass, either by dissolving in the glass or being encapsulated by it.

As the oxygen-to-propane ratio in the flame increases, vaporization also increases. Generally, the largest increase in uranium vaporization occurs if the oxygen-to-propane ratio increases above 4 (stoichiometric flame $=5$ ) and is more pronounced at the higher temperature. This indicates that if uranium vaporization is a problem in the system, decreasing the oxygen-topropane ratio may have a significant effect at reducing the vaporization, although carbon monoxide production then becomes an issue. Under the reducing conditions of an oxygen-topropane ratio of 4 , however, the amount that could vaporize is reduced by $99 \%$ as compared to that vaporized in a stoichiometric flame. Additional calculations show that generally the calculated concentration of uranium in the vapor at equilibrium decreases by approximately one order of magnitude for every $220^{\circ} \mathrm{F}$ drop in temperature down to $2000^{\circ} \mathrm{F}$. This indicates that there is not a specific critical temperature that must be avoided to prevent vaporization, but that vaporization does drop rapidly with temperature. 


\section{PLUTONIUM}

Generally, much less plutonium is expected to be in the vapor during vitrification than uranium; primarily because even at its highest expected concentration in the Vortec feed, there is less than one-millionth as much plutonium as uranium. Because of its low concentration in the feed, there should be less than a part per billion concentration in the flame. As was true for uranium, the plutonium vaporization decreases under slightly reducing conditions, although there is almost no effect at $2800^{\circ} \mathrm{F}$. The biggest effects of flame stoichiometry occur at lower temperatures where several orders of magnitude more plutonium could be present in the vapor under oxidizing conditions than under reducing. However, the concentrations at lower temperatures are in the part per trillion to part per quadrillion level. The primary reduction comes in the concentrations of $\mathrm{PuO}_{3}$ and $\mathrm{PuO}_{3}\left(\mathrm{H}_{2} \mathrm{O}\right)$, whereas $\mathrm{PuO}_{2}$ vaporization is little affected by flame stoichiometry. As was also true for uranium, there is no critical temperature for this system where plutonium vaporization jumps significantly. Instead, like uranium, its log partial pressure decreases fairly linearly with temperature, indicating that the vaporization drops rapidly, but in a smooth fashion, with temperature drop.

Hydroxide, fluorine, and chlorine concentrations in the feedstocks have little influence on plutonium vaporization. In part, this is because they are bound in other forms, especially as sodium, potassium, and hydrogen compounds. Even if the alkali metal concentrations were decreased significantly, the hydrogen forms of these species are much more stable than the plutonium forms. Therefore, as long as a fossil fuel flame is used to heat the Vortec melter, then there will be an excess of water vapor present, and plutonium vaporization as a fluoride, chloride, or hydroxide is predicted to be less than a tenth of a ppb. However, in systems where little water vapor is present and if the alkali metal concentration in the feedstock is less than the amount necessary to absorb the halogens and hydroxide, then the vaporization of plutonium as fluorides, chlorides, or hydroxides could become more significant.

Because of the low maximum concentration of plutonium in the materials to be processed by Vortec, $100 \%$ of it could conceivably vaporize at a flame temperature of $2800^{\circ} \mathrm{F}$. This vaporized plutonium would be expected to essentially completely condense as the gas cooled, possibly even within the melter. The data indicate that if the plutonium concentration is less than approximately one part per million in the waste, then most of it will volatilize. At concentrations above a part per million, the gas stream is saturated, and the remainder goes into the glass. However, this assumes equilibrium conditions. Depending on the association of the plutonium in the waste material, equilibrium probably will not be achieved, so that in actual practice, less plutonium will vaporize than predicted, and more will go into the glass product than the predictions indicate. The most thermodynamically stable solid oxide phase is $\mathrm{PuO}_{2}$, and its chemical stability is independent of the reducing/oxidizing conditions of the propane-air flame.

\section{THORIUM}

Less than three one-thousandths of a percent of the thorium should vaporize in the Vortec melter at $2800^{\circ} \mathrm{F}$ at normal flame stoichiometries and four orders of magnitude less than that at 
$2000^{\circ} \mathrm{F}$. The amount is essentially independent of oxygen to propane ratios, only doubling when going to unrealistically low levels. The most dominant vapor components are $\mathrm{ThF}_{4}$ and $\mathrm{ThO}_{2}$. Increasing fluorine contents will increase the amount of thorium vaporization, but unless levels become exceptionally high, the amount of thorium vaporization will remain very low. In the solid phase, $\mathrm{ThO}_{2}$ dominates.

\section{NEPTUNIUM}

Similar calculations performed for neptunium components has shown that the solid crystalline $\mathrm{NpO}_{2}$ phase is the only stable phase formed below $2800^{\circ} \mathrm{F}$. However, because of the lack of data for vapor species of neptunium, the calculations with the present database for vaporization of the element are not conclusive.

\section{TECHNETIUM}

In the vitrification of nuclear waste, technetium oxides are known to be lost substantially by vaporization, especially under normal oxidizing conditions. The highest oxidation state of Tc is 7 , such as in $\mathrm{Tc}_{2} \mathrm{O}_{7}$. The melting point of $\mathrm{Tc}_{2} \mathrm{O}_{7}$ is $247^{\circ} \mathrm{F}(392.6 \mathrm{~K})$. Reducing conditions lead to the formation of $\mathrm{TcO}_{2}$, which precipitates from the melt. Stronger reducing conditions lead to the formation of metallic Tc.

As was true for plutonium, the very low maximum concentration of technetium in the Vortec wastes and the high volatility of the technetium causes all of the technetium to vaporize in the flame under equilibrium conditions. However, if the feed material is composed of larger pieces and the glass is quickly removed from the melter, there may not be sufficient time for all of the technetium to volatilize. Almost all of the technetium is condensed at $2000^{\circ} \mathrm{F}$ at equilibrium, leaving less than $1 \%$ of the original amount in the vapor phase. The FACT calculations indicate that the vaporized technetium is dominated by $\mathrm{TcO}_{2}$ under oxidizing conditions, but that the concentration of $\mathrm{TcO}$ becomes nearly as great under reducing conditions. Possible chlorine and fluorine species could not be determined because they are not available in the FACT database. As is true for the vapor, $\mathrm{TcO}_{2}$ dominates the condensed phases, especially at higher oxygen partial pressures. However, in order for condensed technetium to be present at equilibrium at $2800^{\circ} \mathrm{F}$, the concentration of technetium in the feed would have to be approximately two orders of magnitude greater than the maximum expected in the Vortec feed materials to be used in the initial 30-day test.

\section{CESIUM}

Cesium $\left({ }^{137} \mathrm{Cs}\right.$ and $\left.{ }^{134} \mathrm{Cs}\right)$ is highly volatile in melter systems. Therefore, it is usually removed from high-level tank wastes by an ion-exchange process using crystalline silicotitanate (CST). Vitrification of the CST is usually performed using a low-temperature grouting process. Because of the extremely low level of cesium in the possible Vortec waste streams, no ion- 
exchange procedure is expected. Thermochemical equilibrium calculations of the vaporization of the cesium were performed to determine which phases would form in the presence of water vapor, fluorine, chlorine, and chromium and approximately at what temperature the cesium components would condense within the Vortec system.

As suggested in the literature, the modeling indicates that all of the cesium present in the possible materials to be vitrified in the Vortec melter vaporizes in the flame. The major vapor phases predicted under oxidizing conditions are $\mathrm{Cs}_{2} \mathrm{CrO}_{4}, \mathrm{CsOH}, \mathrm{CsF}$, and $\mathrm{CsCl}$, while under reducing conditions, cesium metal becomes a significant component. At approximately $1500^{\circ} \mathrm{F}$, the cesium begins condensing from the gas under the oxidizing conditions, while under reducing conditions the condensation does not begin until the temperature drops to approximately $1200^{\circ} \mathrm{F}$. The condensation temperature under oxidizing conditions increases by approximately $100^{\circ} \mathrm{F}$ for every order of magnitude increase in the concentration of cesium in the feedstock. The major condensed phase is $\mathrm{Cs}_{2} \mathrm{Cr}_{2} \mathrm{O}_{7}$ liquid. The material would be expected to begin condensing near the back end of the heat recuperator, either on system surfaces or on entrained particulates, or homogeneously as submicron entrained particulates. However, the concentrations in the vapor would be extremely low; less than a tenth of a part per quadrillion is the most expected based on the maximum level of cesium in the Vortec feedstock expected for the initial 30-day system test.

\section{CONCLUSIONS}

The thermochemical equilibrium calculations indicate that at the temperature of a propane-air flame, some volatilization of uranium, plutonium, technetium, and cesium will occur. The expected concentrations of plutonium, technetium, and cesium in the flame will be very low because of the small maximum concentration of these elements in the projected feed materials for the first 30-day test. The quantities volatilized can generally be decreased by operating the flame in a fuel-rich mode, although this will lead to greater carbon monoxide production, which may be more objectionable. The concentrations of chlorine and fluorine, at least at the maximum levels in the projected Vortec feed, are not projected to greatly influence the vaporization rates. Therefore, blending to reduce the concentrations of those elements would most likely not be effective in reducing metal vaporization. Most of the elements vaporized condense by the time the gas cools to $2000^{\circ} \mathrm{F}$. These elements would condense either on surfaces near the front of the heat recuperator or on entrained particulates or homogeneously as relatively pure submicron particles. Cesium would be expected to condense at the lower temperatures near the rear of the recuperator, although the expected maximum concentration in the Vortec feed material is extremely low so it should be greatly diluted by other particulates. The elements that condense on other entrained particles will form enriched surface coatings. Particles larger than $10 \mu \mathrm{m}$ or so will be collected in the scrubber. Smaller particles, especially the submicron particles formed from homogeneous nucleation, should be largely collected in the HEPA filter.

Deposits formed in the heat recuperator can normally be handled via sootblowing. To reduce handling problems, we suggest that the recuperator be oriented vertically so that the deposits blown off of the heat exchanger fall directly into the molten glass. The large size of the deposits should help to reduce the rate of revaporization, allowing the volatile elements to be 
removed with the glass. The volatile elements that do not deposit on system surfaces will be concentrated in the smaller particles. Therefore, the HEPA ash will be greatly enriched in these elements. If the HEPA filter is itself sent to a melter, the elements may revaporize and multiply the problems related to metal vaporization significantly. Therefore, the HEPA filters should be disposed of without high-temperature processing. Also, to reduce the formation of these very small particles, it is helpful to include in the feed larger particles to act as condensation nuclei that can then be collected in the scrubber. This can be accomplished by using feed materials with a fraction consisting of particles small enough that they will not be collected in the cyclone in the melter, but large enough that they will easily be collected by the scrubber. This is one advantage that firing bituminous coal has over gas firing; it provides a source of ash particles of the right size range to serve as nucleation sites, but large enough (depending on the coal) so that they can usually be collected efficiently in the scrubber system. 


\section{TASK 23 - THERMODYNAMIC MODELING OF VOLATILE HAZARDOUS METAL BEHAVIOR IN THE VORTEC VITRIFICATION SYSTEM}

\subsection{INTRODUCTION}

In the nuclear industry, considerable amounts of by-products containing transuranic elements are produced each year. These nuclear wastes must be disposed of safely for $10^{3}-10^{5}$ years, as required by regulatory agencies. An important method being developed for long-term storage of nuclear wastes includes incorporating the waste into a glass form. Vitrification methods include fossil fuel-fired melters, plasma torch centrifugal reactors, or Jouleheated melters. Energy \& Environmental Research Center (EERC) experience with coal-fired thermal energy systems has shown that portions of the inorganic material inherent in the fuel vaporizes during heating. Vaporization can occur either through physical vaporization or through chemical reactions, especially in the presence of sulfur, halides, or water vapor. It is likely that in a waste melter, some vaporization also occurs, not just from a solid or liquid fuel, but from the wastes themselves. Downstream of a melter, the vapor species can condense, possibly forming fine particulates or even massive deposits that are highly concentrated in specific elements. In proprietary EERC work, element enrichment factors of up to 50,000 times have been measured in massive coal ash deposits as compared to the fuel. Such enrichments of radioactive or Resource Conservation and Recovery Act (RCRA) elements in a melter could produce hazardous deposits at specific sites within the system. However, knowledge of the vaporization and condensation behavior of the hazardous elements can be used to propose simple methods to prevent such problems from occurring.

The primary activity of Task 23 is to perform thermochemical equilibrium computer modeling to provide a background of information on the possible vaporization and condensation behavior of radionuclides and RCRA elements in a propane-air flame. Two temperatures in or near the flame were modeled, $2000^{\circ}$ and $2800^{\circ} \mathrm{F}$, in a broad range of oxygen-propane ratios (1.5-7.0). The work is being done in cooperation with the Vortec Corporation of Collegeville, Pennsylvania. Vortec is building a demonstration fossil energy-fired vitrification system at the Paducah Gaseous Diffusion Plant near Paducah, Kentucky. The Vortec cyclone melter system is designed to process 36 tons/day of as-received drummed or bulk wastes. The processing capacity equates to approximately 160 barrels/day of waste materials containing $30 \%$ moisture at an average weight of $450 \mathrm{lb} / \mathrm{b}$ arrel.

The goal of the activity is to use the results of the computer modeling to help predict the potential for operational difficulties in gas-fired waste melters such as the creation of hazardous submicron particulates that could rapidly clog high-efficiency particulate air (HEPA) filters or the formation of deposits containing high concentrations of hazardous species. By modeling the vaporization/condensation behavior of hazardous metals within the melter, we can determine and quantify factors affecting the development of such operational issues. Once this information is obtained, simple methods to prevent their occurrence can be delineated. They include on-line control with sootblowers, installation of access panels at specific locations to allow hot off-line deposit removal, or minimizing vaporization by appropriate selection of feedstocks or blending 
scenarios or operating the burner in fuel-rich or -lean modes. Such preventive actions will help to decrease operational difficulties, substantially increase system availability, and minimize problems related to the removal and disposal of deposits enriched in hazardous materials.

\subsection{VAPORIZATION AND CONDENSATION BEHAVIOR OF ELEMENTS IN COMPLEX THERMAL SYSTEMS}

Indications of possible vaporization and condensation behavior of radionuclides or RCRA elements in fossil-fueled vitrification systems can be inferred from the behaviors of inorganic materials in other fossil-fueled thermal systems. In particular, the EERC has a large knowledgebase of data and experience with the inorganic materials in coal-fired power plants. Analyses of coal, entrained ash, and ash deposits collected from utility boiler systems have shown that inorganic matter can volatilize in the flame through either physical or chemical means. In cooler regions downstream of the flame, the volatilized components can condense, again, either through physical or chemical means.

Figure 1A shows the concentrations of several major elements in massive ash deposits collected from a coal-fired utility boiler as compared to the approximate deposit temperature. The data, reported as oxides on a sulfur oxide-free basis (except for sulfur oxide), show slightly higher concentrations of silica and calcia in the deposits at higher temperatures than at lower temperatures. This occurs because calcium-rich silicate particles are stickier at higher temperatures, and so even larger particles stick more effectively when they collide with a boiler surface. At lower temperatures, the particles are less sticky and tend to bounce of surfaces that they impact.

In contrast, the change in sulfur in the deposits is striking. At temperatures above $2000^{\circ} \mathrm{F}$, the deposits contain relatively little sulfur. Below $2000^{\circ} \mathrm{F}$, they contain over $25 \%$ when reported as sulfur trioxide. The sulfur enrichment occurs through chemical vapor deposition (CVD). Below $2000^{\circ} \mathrm{F}$, calcium becomes more chemically stable as calcium sulfate, rather than the calcium silicate that is more stable at higher temperatures. Therefore, the calcium that deposited as calcium silicate converts to a sulfate by absorbing sulfur oxide from the gas stream.

Figure 1B shows that like the sulfur concentrations, the sodium and potassium concentrations in the deposits, reported as oxides, increase significantly below $2000^{\circ} \mathrm{F}$. These elements are present in the deposits as sulfates that deposit either by simply condensing via physical vapor deposition (PVD) or by CVD via converting from gaseous hydroxides to condensed sulfates.

Whether condensing to form deposits via PVD or CVD, it is clear that elements that vaporize in the flame can be either enriched or depleted in ash deposits, depending on the deposit temperature. In cases where little other ash deposits, the deposits can be very highly enriched in certain species as compared to the composition of the feed material. In proprietary research, the EERC has analyzed samples of massive deposits that have formed in coal-fueled systems that arecomposed primarily of elements present in the feedstock in levels of $10 \mathrm{ppm}$ or less. 


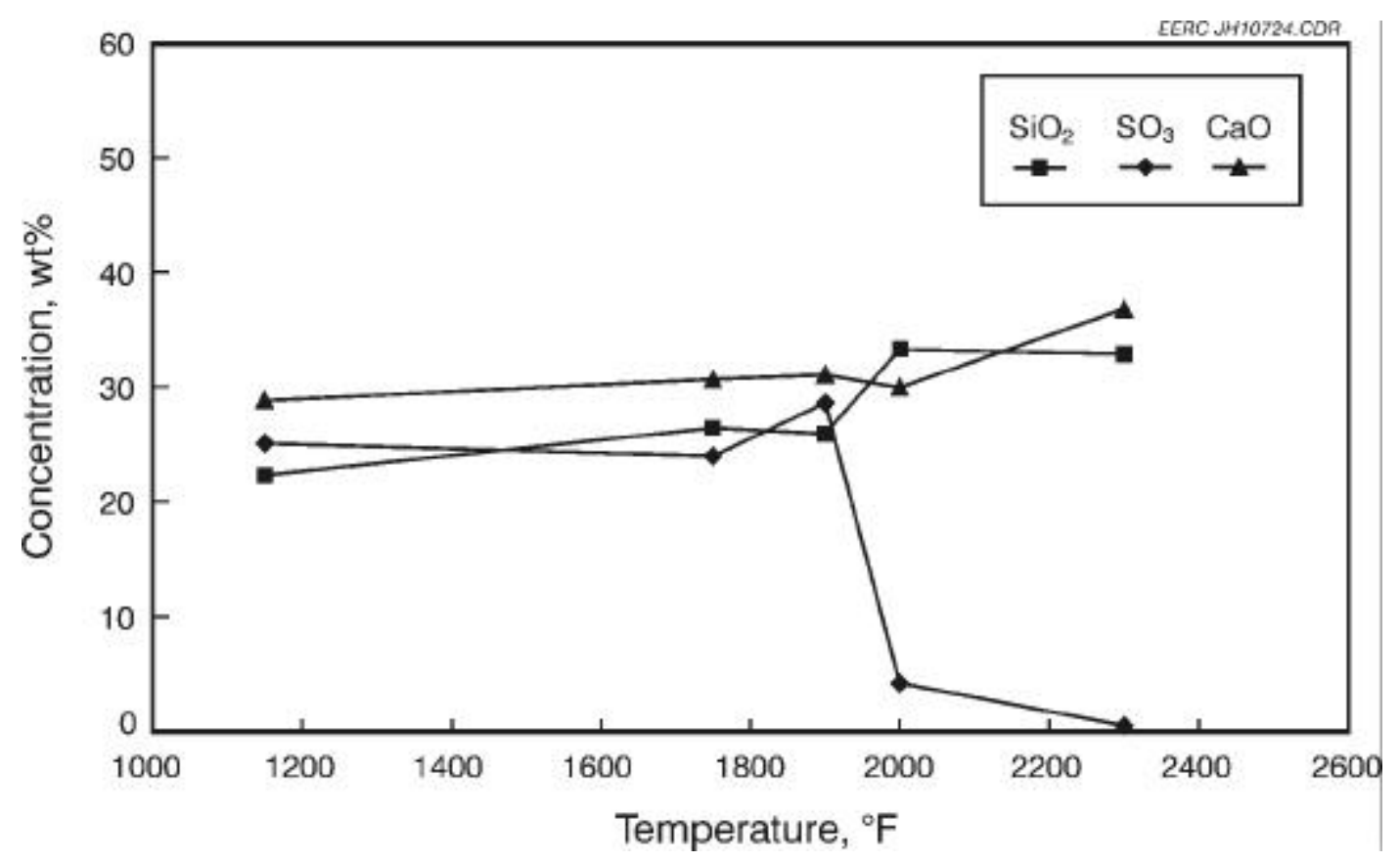

(A)

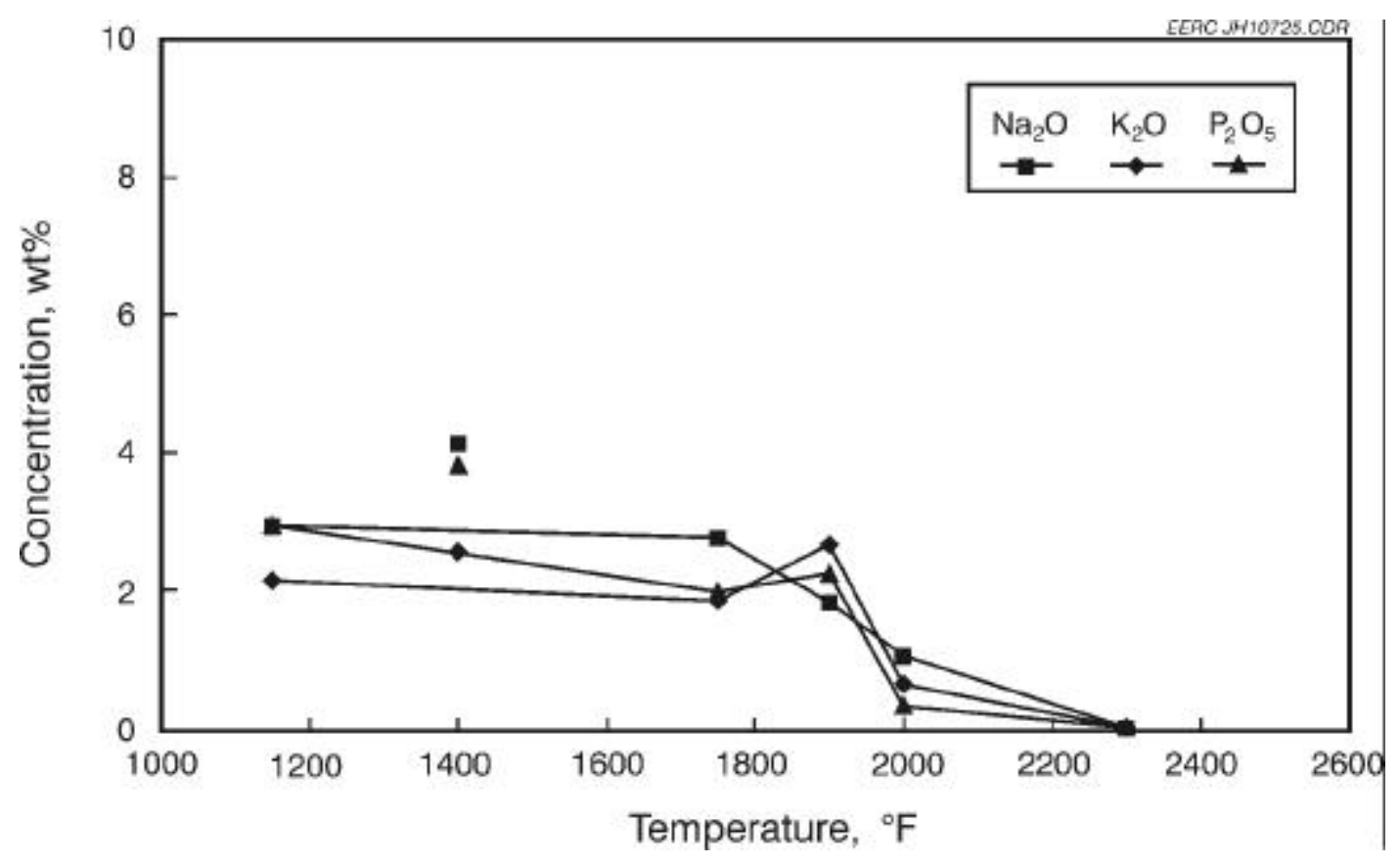

(B)

Figure 1. Concentrations of elemental oxides in coal ash deposits formed in a utility boiler as compared to the temperature of the deposit. Data are presented as oxides on a sulfur-free basis. 
Enrichment factors in such cases may approach a level of 50,000 times. If such enrichments occur in melters handling RCRA or radioactive wastes, very hazardous deposits could form downstream of the flame.

\subsection{THERMOCHEMICAL EQUILIBRIUM MODELING}

In order to determine the probability of significant enrichment of RCRA or radioactive elements in deposits formed in hazardous waste melters, the vaporization and condensation behavior of the elements must be predicted. With these predictions, methods of preventing the enrichment may be developed. Physical vaporization of pure compounds is a special case of phase transition that is usually described by an enthalpy of phase transition, also called the latent heat of vaporization. In a phase change, there is a substantial change of volume, so that internal energy change, $\Delta \mathrm{U}$, and enthalpy change, $\Delta \mathrm{H}$, may differ significantly. Therefore, Gibbs free energy is used to describe the behavior of compounds under conditions of equilibrium and the direction of chemical change. However, the vaporization of a pure compound may be larger in the presence of gases such as fluorine, chlorine, and water vapor, and this can be regarded as the sum of additional chemical contributions in attaining a new equilibrium. With a thermochemical equilibrium model, it is possible to describe the possible transformations between several internally thermodynamically stable states of a system.

Version 3.0 of the Facility for the Analysis of Chemical Thermodynamics, or FACT code, was used for the modeling done in this project. The FACT 3.0 program is especially useful in quantifying chemical equilibria in complex ceramic materials such as ashes and slags. It was developed at the Ecole Polytechnique de Montréal. This model is a descendant of the SOLGASMIX code and is also based on Gibbs free energy minimization. The FACT code predicts partial pressures of vapor, liquid, and solid stable components over a broad range of temperatures. The advantage of the FACT model over other codes is the amount of species in the thermochemical database (over 7000), the number of elements and species that can participate in complex reactions, and the ability to optimize solutions representing nonideal mixing in complex melts.

For modeling in the Vortec melter system, the FACT modeling program is being used to evaluate the partial pressures of major components in a flame derived from $\mathrm{CN}, \mathrm{F}, \mathrm{Cl}, \mathrm{S}, \mathrm{OH}, \mathrm{U}$, $\mathrm{Pu}, \mathrm{Th}, \mathrm{Np}, \mathrm{Tc}$, and $\mathrm{Cs}$. The maximum concentrations expected in the possible waste materials to be vitrified by Vortec during a 30-day test period early in the operation of the system were used for the calculations. They were provided by Vortec and are listed in Tables 1 and 2. The last row in Table 1 represents the sum of total other species in the waste stream that were either radioactive, and so included in Table 2, or were not considered important in the calculations (trace elements, organics). The last column in each table lists the mole fraction of the elemental oxide or isotope in the total feed into the melter (solid + air + propane), not including any glass cullet. These are the numbers that are entered into the FACT code calculations. The code can predict mole fractions (partial pressures, between 1 and $10^{-30}$ atm.) of vapor-phase components over a broad range of temperatures and selected pressures. It is assumed that each component in the vapor phase behaves as an ideal gas, so the partial pressure is proportional to the mole 


\section{TABLE 1}

Constituents in RCRA Stream Used for Thermodynamic Calculations

\begin{tabular}{lrccc}
\hline Element & $\begin{array}{c}\text { Max. Conc. in } \\
\text { RCRA Stream, } \\
\text { mg/kg }\end{array}$ & $\begin{array}{c}\text { Max. Conc. in } \\
\text { RCRA Stream } \\
\text { (normalized } \\
\text { mass fraction) }\end{array}$ & $\begin{array}{c}\text { Max. Oxides Conc. } \\
\text { in RCRA Stream } \\
\text { (normalized } \\
\text { mass fraction) }\end{array}$ & $\begin{array}{c}\text { 0.2 Mole Fraction of } \\
\text { Oxides in Total } \\
\text { Melter Feed (applied } \\
\text { for FACT } \\
\text { calculations)* }\end{array}$ \\
\hline $\mathrm{Al}$ & 410,000 & 0.09599 & 0.1371 & 0.02368 \\
$\mathrm{Ca}$ & 165,000 & 0.03863 & 0.0408 & 0.01283 \\
$\mathrm{Cr}$ & 290,000 & 0.06790 & 0.0749 & 0.00868 \\
$\mathrm{Fe}$ & 133,000 & 0.03114 & 0.0336 & 0.00371 \\
$\mathrm{Mg}$ & 47,900 & 0.01121 & 0.0014 & 0.00613 \\
$\mathrm{Ni}$ & 244,000 & 0.05713 & 0.0549 & 0.01295 \\
$\mathrm{P}$ & 18,278 & 0.00428 & 0.0074 & 0.00092 \\
$\mathrm{~K}$ & 92,000 & 0.06836 & 0.0622 & 0.01989 \\
$\mathrm{Si}$ & 355,000 & 0.08312 & 0.1305 & 0.03828 \\
$\mathrm{Na}$ & 478,000 & 0.11192 & 0.1478 & 0.04201 \\
$\mathrm{Zn}$ & 4,400 & 0.00103 & 0.0009 & 0.00021 \\
$\mathrm{~F}$ & 54,406 & 0.03615 & 0.0388 & 0.01267 \\
$\mathrm{Cl}$ & 8,200 & 0.00192 & 0.0029 & 0.00058 \\
$\mathrm{~S}$ & 11,580 & 0.00271 & 0.0041 & 0.00113 \\
Others & balance & 0.38851 & 0.2627 & 0.01633 \\
\hline
\end{tabular}

* 0.8 remaining mole fraction is the propane and air.

TABLE 2

Radionuclide Concentrations Used for Thermodynamic Calculations

\begin{tabular}{|c|c|c|c|c|c|}
\hline Isotope & Mass $(\mathrm{g})$ in $1 \mathrm{Ci}^{*}$ & $\begin{array}{l}\text { Max. Conc. in } \\
\text { RCRA Stream } \\
\text { in pCi/g }\end{array}$ & $\begin{array}{l}\text { Max. Conc. in } \\
\text { RCRA Stream } \\
\text { (g element per } \\
\text { g total) }\end{array}$ & $\begin{array}{c}\text { Max. Conc. in } \\
\text { RCRA Stream } \\
\text { (normalized } \\
\text { mole fraction) }\end{array}$ & $\begin{array}{l}0.2 \text { Mole Fraction } \\
\text { of Elements in } \\
\text { total Melter Feed } \\
\text { (applied for } \\
\text { FACT } \\
\text { calculations)** }\end{array}$ \\
\hline U234 & $1.62 \mathrm{E}+02$ & 41,700 & $6.7 \mathrm{E}-06$ & & \\
\hline U236 & $1.58 \mathrm{E}+04$ & 2,990 & $4.72 \mathrm{E}-05$ & Total U234-8 & \\
\hline U238 & $3.00 \mathrm{E}+06$ & 218,000 & $6.541 \mathrm{E}-01$ & $1.54 \mathrm{E}-02$ & $3.08 \mathrm{E}-03$ \\
\hline Th230 & $5.15 \mathrm{E}+01$ & 36,160 & $1.86 \mathrm{E}-06$ & Total Th230-2 & \\
\hline Th232 & $9.14 \mathrm{E}+06$ & 0.2979 & $2.72 \mathrm{E}-06$ & $1.1 \mathrm{E}-07$ & $2.16 \mathrm{E}-08$ \\
\hline Тc99 & $5.87 \mathrm{E}+01$ & $248,293.4$ & $1.45 \mathrm{E}-05$ & $3.4 \mathrm{E}-07$ & $6.8 \mathrm{E}-8$ \\
\hline Pu239 & $1.63 \mathrm{E}+01$ & 10,830 & $1.76 \mathrm{E}-07$ & $4.1 \mathrm{E}-9$ & $8.2 \mathrm{E}-10$ \\
\hline $\mathrm{Np}$ & $1.42 \mathrm{E}+03$ & 19,900 & $2.82 \mathrm{E}-05$ & $6.6 \mathrm{E}-07$ & $1.3 \mathrm{E}-07$ \\
\hline Cs & $7.68 \mathrm{E}-04$ & 18.28 & $1.4 \mathrm{E}-14$ & $3.3 \mathrm{E}-16$ & $6.6 \mathrm{E}-17$ \\
\hline
\end{tabular}

* 1 Ci represents 1 curie.

** 0.8 remaining mole fraction is the propane and air. 
fraction (Dalton's law). It was assumed that the significant partial pressures in the deposition (condensation) process are in the range of 1 to $10^{-10} \mathrm{~atm}$. In the flame, stable equilibria are seldom reached; however, an equilibrium analysis can give insight into possible vaporization and chemical reactions that may occur under given conditions of composition, temperature, and pressure. It was also assumed that the vapor-phase products formed at high temperatures are transported by the flue gas to lower temperatures and condensed. It is important to realize however, that uncertainties will occur in the prediction of vaporization and condensation behavior if components that may form during operation of the Vortec system are not included in the FACT code database because of lack of thermodynamic data.

The condensation calculations were performed in a series of steps in order to diminish the effect of competing system conditions. The maximum number of species that can be selected for FACT code calculation is 628 . However, the number of possible compounds in the database that may exist in the vapor phase is about 500, in the liquid phase about 150 , and in the solid phase about 700. In order to get more accurate results, thermodynamic calculations were separated into several sections:

- Calculation of partial pressures of all vaporization-inducing components formed from the combustion of the propane and from the easily vaporized components in the waste such as fluorine, chlorine, and sulfur. Calculations were limited to those in a range of partial pressures from 1 to $10^{-30}$ atmospheres. This permitted an accurate calculation of the $\mathrm{CN}$, $\mathrm{NH}_{3}, \mathrm{NO}_{\mathrm{x}}, \mathrm{F}, \mathrm{Cl}, \mathrm{OH}$, and $\mathrm{S}$ components formed in an exhausted gas at temperatures between $2000^{\circ}$ and $2800^{\circ} \mathrm{F}$. It was assumed that the fluctuation of propane-to-air ratio in the flame may contribute to the fluctuation of the partial pressures in the gas; therefore, we allowed the propane- $\mathrm{O}_{2}$ ratio to vary below and above the stoichiometric reaction (Eq. 1) that may represent both reducing (starting from 1.5) and oxidizing (ending on 7.0) conditions:

$$
\mathrm{C}_{3} \mathrm{H}_{8}+5 \mathrm{O}_{2} \rightarrow 3 \mathrm{CO}_{2}+4 \mathrm{H}_{2} \mathrm{O}
$$

The strategy is to determine whether small changes in oxygen content in the gas may reduce the formation of certain gaseous species that enhance the vaporization of the RCRA and radioactive elements. Also, to determine the standard enthalpy change for all possible exo- and endothermic chemical reactions that can arise in the flame.

- Calculation of partial pressures of all species derived from the nonradioactive solid phases (Table 1) plus uranium (Table 2) and propane and air, under both reducing and oxidizing conditions at $2000^{\circ}$ and $2800^{\circ} \mathrm{F}$. In this stage, the gas concentration derived from the waste was limited to partial pressures above $10^{-11}$ atm, keeping the uranium component partial pressures between 1 and $10^{-30}$ atm. Particular attention was given to $\mathrm{F}, \mathrm{Cl}, \mathrm{OH}$, and $\mathrm{S}$ components in the vapor phase. It was assumed that only $20 \%$ of the mass injected into the flame is composed of silicates and uranium, the rest being the propane and air. It was found that larger silicate and uranium contents in the flame do not significantly change the chemical equilibria. The calculated results are expressed 
either as the log partial pressures of vapor components or the percentage of total uranium in the vapor phase.

- Calculation of partial pressures of all species derived from the nonradioactive solid phases (Table 1) plus plutonium (Table 2) and propane and air, under both slightly reducing and slightly oxidizing conditions at $2000^{\circ}$ and $2800^{\circ} \mathrm{F}$. The calculation procedure was similar to that described above.

- Application of a similar program of thermodynamic calculations for cesium and other radionuclides in a RCRA stream (Table 2). The results are expressed either as the log partial pressures of vapor components or the percentage of total radionuclides in the vapor phase.

- Calculations of mole fractions of solid and liquid phases condensed from the vapor phase at lower temperatures downstream of the flame and partial pressures of remaining species in the vapor phase. In these calculations, we introduced all vapor components formed at $2000^{\circ}$ and $2800^{\circ} \mathrm{F}$ with partial pressures from 0 to $10^{-10} \mathrm{~atm}$. We restricted our calculations to major radionuclide, silicate, and vaporization-enhancing gas components such as $\mathrm{Cl}, \mathrm{F}, \mathrm{S}$, and water vapor.

Because the FACT code does not include many of the RCRA or radioactive elements as components in complex silicate slags, but as separate solid and liquid phases, it was assumed that solid phases such as uranium and plutonium oxides that are not vaporized in the flame are either dissolved or encapsulated in the silicate melt. The former assumption has already been verified in experimental work (1). The polynomial and sublattice models were used for the identification of the solutions in this study. Generally, the composition of silicate melts was not significantly changed by incorporating these components. The melts also contained only very small molar fractions of sulfates and phosphates.

\subsection{NITROGEN, CHLORINE, FLUORINE, SULFUR, AND OH COMPONENT DISTRIBUTIONS IN THE FLAME}

\subsection{Nitrogen-Derived Components and CO Emission}

It has long been recognized that nitrogen-derived compounds such as $\mathrm{HCN}, \mathrm{CN}$, and $\mathrm{NO}_{\mathrm{x}}$ can be produced, along with major products such as carbon dioxide and water vapor, during the combustion of propane in air. There is an increasing interest by Vortec Corporation and regulatory agencies to limit nitrogen-derived components in emissions. It is known that the nitrogen products in the exhaust gases depend on the oxygen-propane ratio in the flame. Therefore, thermodynamic calculations were performed to determine the type of control that can be achieved simply by varying the propane-to-air ratio. In the calculations, the air volume was kept at the same level, while the propane volume was changed (Table 3). 
TABLE 3

Thermodynamic Calculations for Propane-Air Mixtures (quantities expressed in mole fractions)

\begin{tabular}{lccccc}
\hline \multirow{2}{*}{$\begin{array}{l}\text { Propane: } \\
\text { Air }\end{array}$} & \multirow{2}{*}{$\begin{array}{c}\text { Mole Fraction } \\
\text { of Propane }\end{array}$} & \multicolumn{2}{c}{ Normalized Mole Fraction } & \\
\cline { 3 - 5 } in a Flame & Added to Air & Propane & $\mathrm{N}_{2}$ & $\mathrm{O}_{2}$ & $\mathrm{O}_{2}$-Propane \\
\hline $0.03: 1.0$ & 0.03 & 0.029 & 0.777 & 0.194 & 6.70 \\
$0.04: 1.0$ & 0.04 & 0.039 & 0.769 & 0.192 & 4.92 \\
$0.06: 1.0$ & 0.06 & 0.057 & 0.754 & 0.189 & 3.31 \\
$0.1: 1.0$ & 0.10 & 0.091 & 0.727 & 0.182 & 2.00 \\
$0.2: 1.0$ & 0.20 & 0.167 & 0.666 & 0.167 & 1.00 \\
\hline
\end{tabular}

Although actual quantities of the different nitrogen-based species and carbon monoxide produced will be affected by reaction rates and burner design, the output of the thermochemical equilibrium modeling can indicate approximate ratios of oxygen-to-propane at which sudden changes in production of troublesome species may occur. Figures 2 and 3 illustrate the log partial pressure change of major nitrogen-derived species and $\mathrm{CO}$, respectively, as a function of propane content in the flame for two temperatures. Figure 4 shows the standard enthalpy change for all chemical reactions that occur in the flame at the same temperatures. As expected, the calculations show that the nonoxide nitrogen species increase and nitrogen oxides decrease as the oxygen-topropane ratio decreases. Also as expected, lower quantities are produced at the lower temperature modeled $\left(2000^{\circ} \mathrm{F}\right)$. For nonoxide nitrogen species, there is a linear increase in production as oxygen-to-propane ratio decreases at $2800^{\circ} \mathrm{F}$ and a jump in production below the stoichiometric ratio of 5 at $2000^{\circ} \mathrm{F}$. For $\mathrm{NO}_{\mathrm{x}}$ species, there is a more linear decline in concentration as oxygen contents are reduced, until the oxygen-to-propane ratio reaches 2 , at which point the production of these species drops significantly. However, as Figure 4 indicates, at this ratio endothermic reactions balance exothermic reactions; i.e., a flame could not be sustained, so operation at this low ratio to reduce $\mathrm{NO}_{\mathrm{x}}$ formation is not feasible. In addition, lowering the oxygen concentration to reduce nitrogen oxide formation increases carbon monoxide production. The calculated amount produced increases steadily as oxygen content decreases. There is no jump in production at a specific oxygen-to-propane ratio, although operation at a lower temperature clearly decreases production in the suprastoichiometric range.

\subsection{Vapor Concentrations of Fluorine, Chlorine, Hydroxyl, and Sulfur Species}

Figure 5 illustrates the total concentrations of F-, Cl-, OH-, and $\mathrm{S}$ - containing species in and around the flame as a function of oxygen-to-propane ratio and temperature. The calculations were made with the assumption that the molar fraction of material added to the melter that was waste material was kept constant at 0.2 . In other words, $20 \%$ (molar) of the material fed was solid, and $80 \%$ (molar) was air + propane. However, oxygen-to-propane ratios were calculated based on the propane-to-air ratios shown in Table 3, which caused the oxygen-to-propane ratios to shift slightly from those in Figures 2-4. The solid material used in the calculations was 

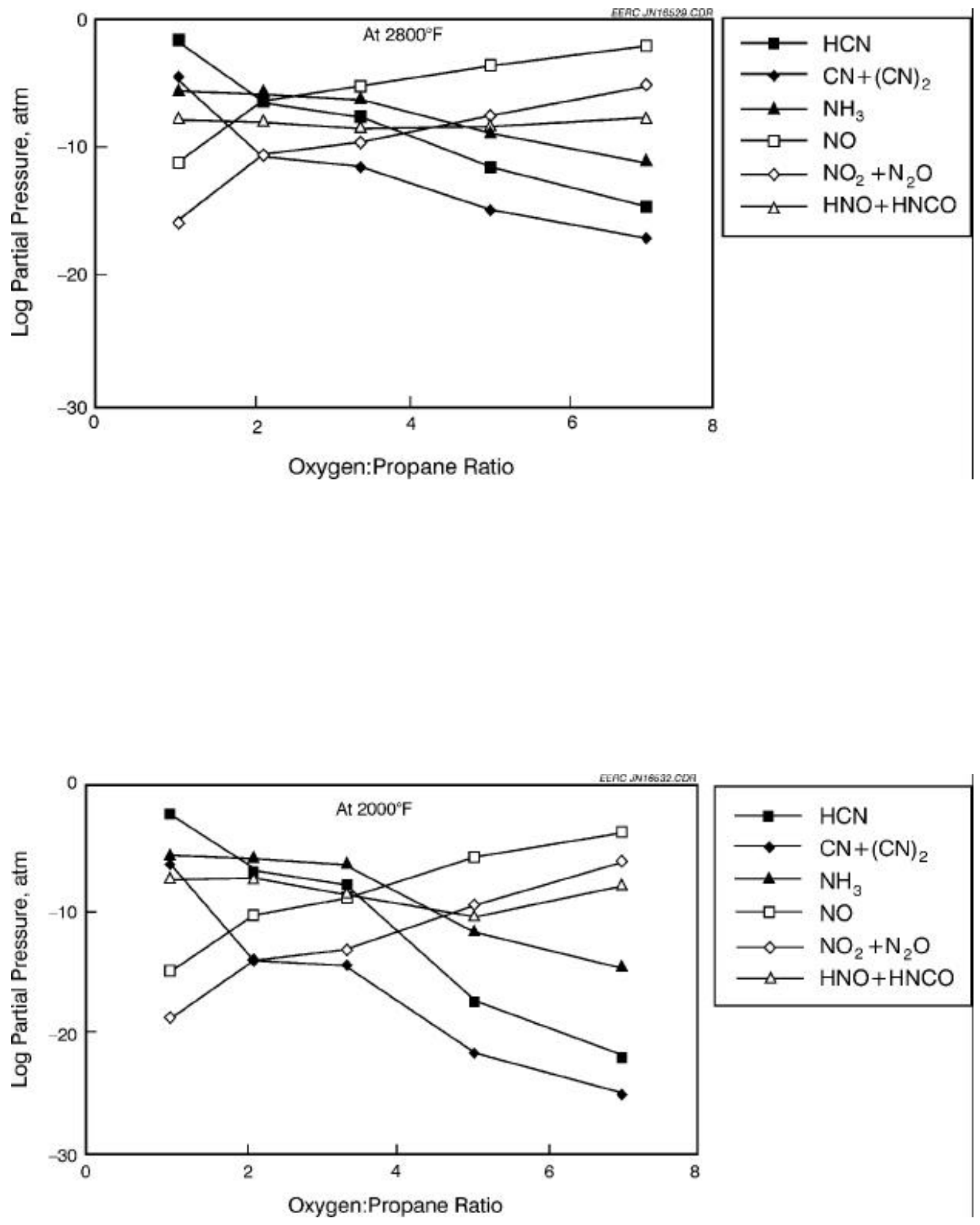

Figure 2. Concentrations of nitrogen-derived components in combusted propane as a function of oxygen-to-propane ratio and temperature. 


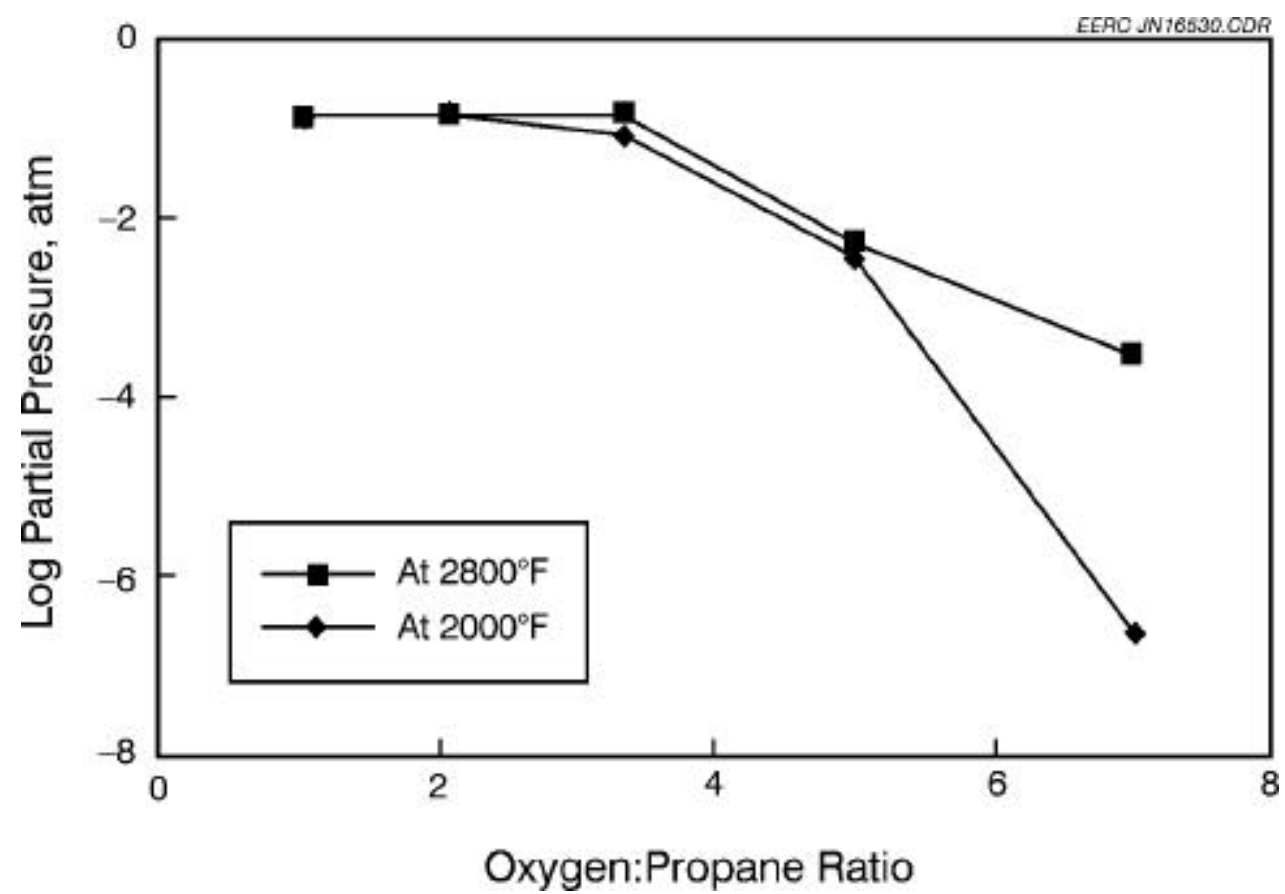

Figure 3. Concentration of $\mathrm{CO}$ in combusted propane as a function of oxygen-to-propane ratio and temperature.

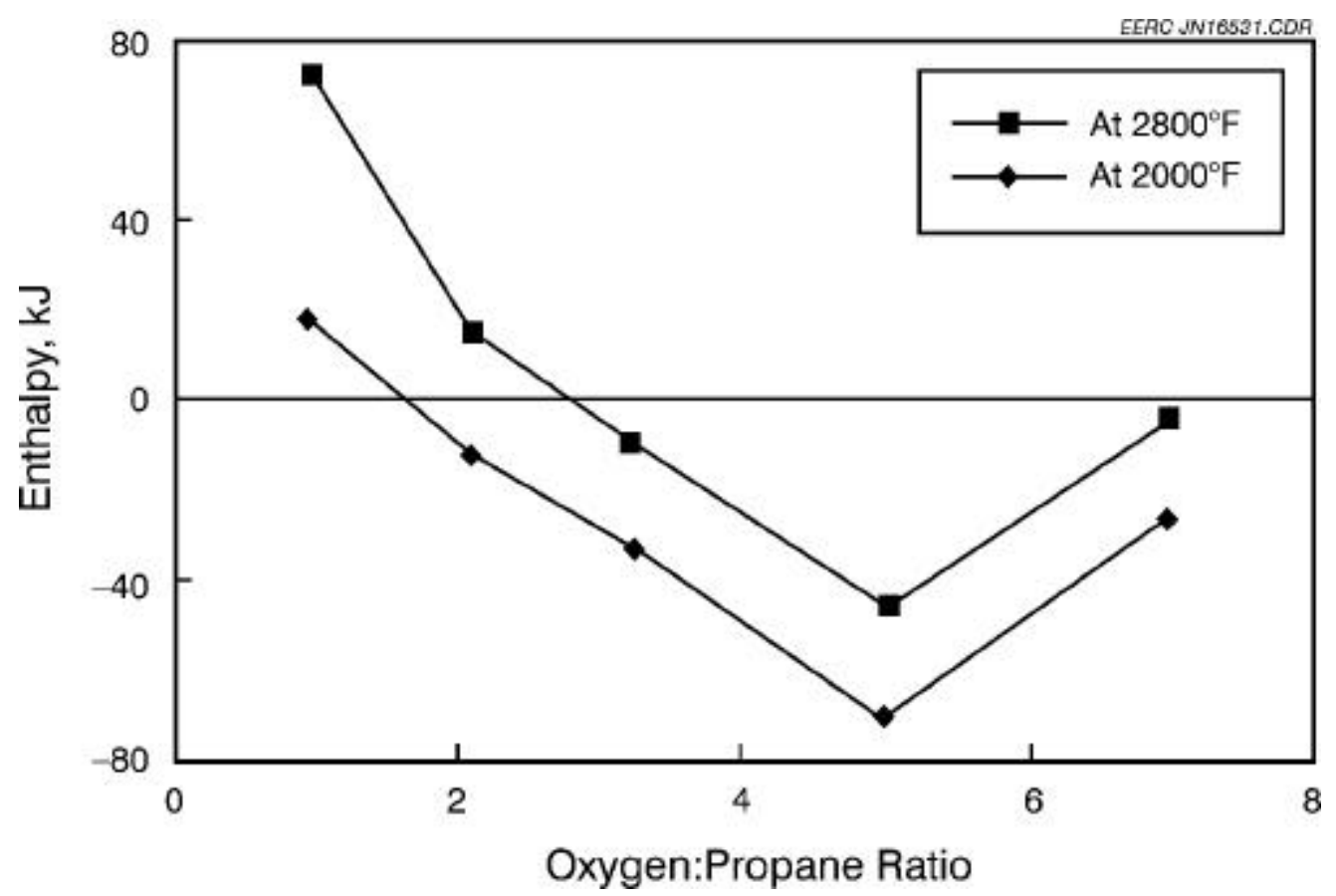

Figure 4. The standard enthalpy change for all possible reactions in the propane-air flame as a function of oxygen-to-propane ratio and temperature. 


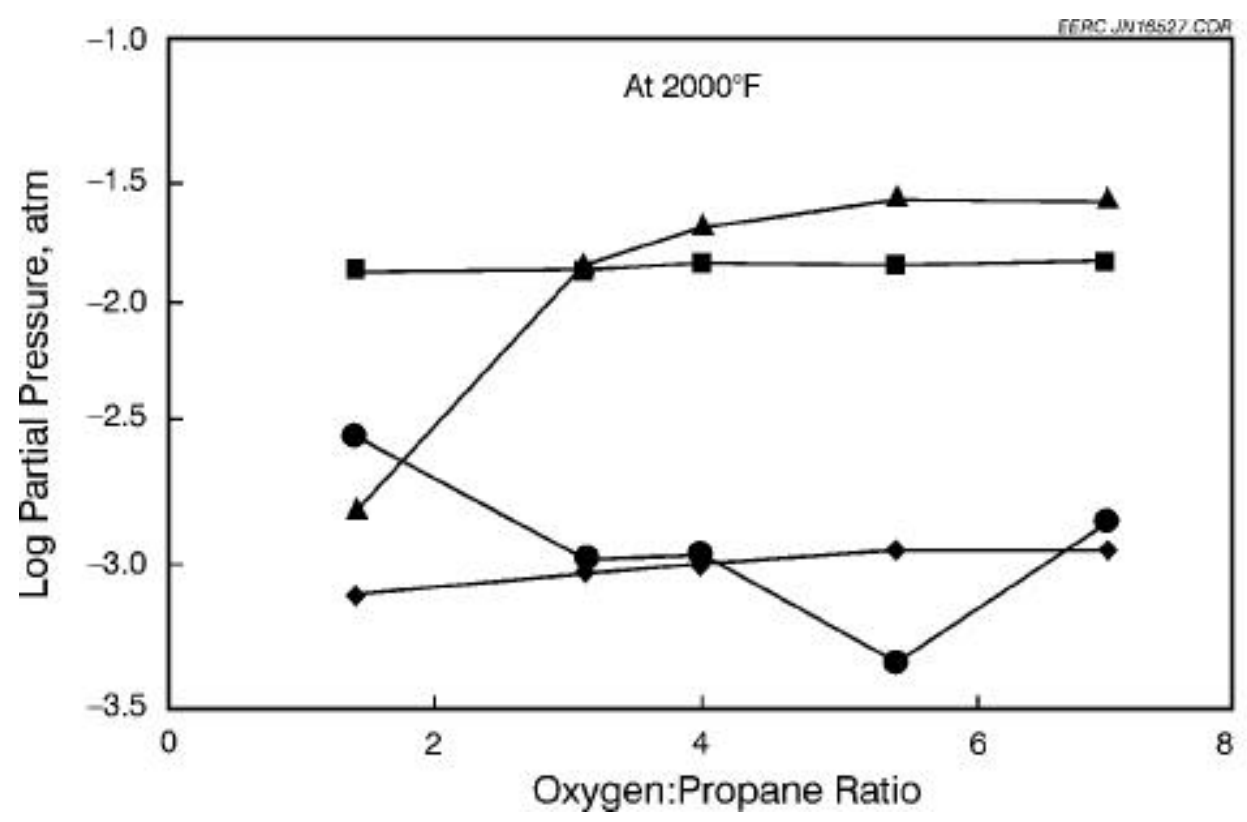

$\longrightarrow$ F Comp.

$\longrightarrow \mathrm{Cl}$ Comp.

$\simeq$ OH Comp.

$\longrightarrow$ S Comp.
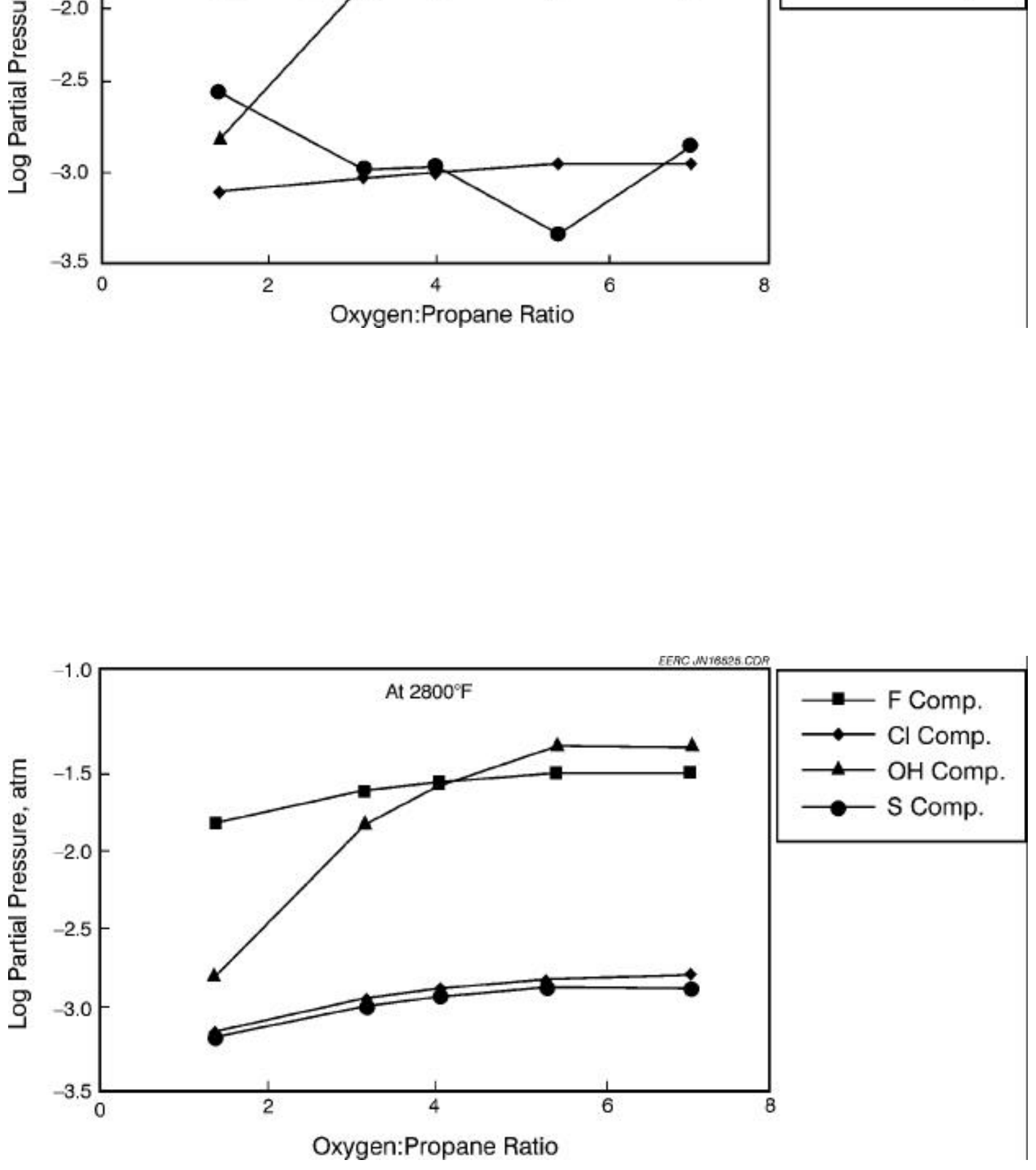

Figure 5. Composition distribution of $\mathrm{F}, \mathrm{Cl}, \mathrm{OH}$, and $\mathrm{S}$ components in the vapor phase. 
composed of a waste stream with the maximum normalized RCRA elemental oxide concentrations possible, as shown in Table 1. No added glass cullet was included in the calculation of the feed stream composition.

Generally, the calculated $\mathrm{F}, \mathrm{Cl}, \mathrm{OH}$, and $\mathrm{S}$ component concentrations in the vapor phase are high because they are based on the maximum concentrations found in all possible feedstocks to the Vortec melter (Table 1). Estimates of the relative proportions of the total $\mathrm{F}, \mathrm{Cl}, \mathrm{OH}$, and $\mathrm{S}$ species in the vapor phase are shown in Figure 5 as functions of temperature and oxygen-topropane ratio. The graphs indicate that hydroxides are in greatest concentrations within the normal operations of a burner, i.e., near the stoichiometric oxygen-to-propane ratio of 5. They are followed closely by fluorides, with chlorides and sulfur species over an order of magnitude lower. Concentrations are approximately $50 \%\left(10^{0.2}\right)$ higher at $2800^{\circ}$ than at $2000^{\circ} \mathrm{F}$, but are relatively unaffected by oxygen-to-propane ratio within the normal operating range. One possible exception is sulfur species which are less vaporized at the stoichiometric ratio than either above or below that ratio. Breakdowns of individual species are shown in Figures 6-9.

\subsubsection{Flourine-Containing Species}

Figure 6 shows that at the maximum fluorine feed rate, vapor-phase species of fluorine are dominated by potassium fluorides, with about an order of magnitude less hydrofluoric acid and another order of magnitude less sodium fluoride at $2000^{\circ}$ and nickel and sodium fluorides at $2800^{\circ} \mathrm{F}$. The relative stability of nickel fluoride vapor of this system indicates not only that a significant amount of nickel will volatilize from the waste stream, but also that nickel-based structural alloys may suffer significant loss when high-fluorine wastes are melted.

Essentially all of the fluorine is in the vapor phase at both $2800^{\circ}$ and $2000^{\circ} \mathrm{F}$, and there is essentially no influence of oxygen-to-propane ratio on the vaporization or condensation of fluorine species in this temperature range. However, if some fluorine remains condensed in the melt, it can affect a number of glass properties such as viscosity, conductivity, durability, and liquidus temperature. The most important is the effect of fluorides on crystallization of silicate glasses. The fluoride suppresses the formation of nonflouride-containing crystals in the composition range from 0 to $11 \mathrm{wt} \% \mathrm{~F}$; above $11 \mathrm{wt} \%$ fluorine, the liquidus temperature of the melt can be reduced (2).

\subsubsection{Chlorine-Containing Species}

Figure 7 shows the calculated maximum concentrations of chlorine-containing species in the gas streams. As was true for fluorine, all of the chlorine vaporizes, and the vapor phases are dominated by potassium chloride, with sodium and nickel chloride three orders of magnitude less at $2800^{\circ} \mathrm{F}$, but sodium chloride only 2 orders of magnitude less at $2000^{\circ} \mathrm{F}$. Nickel chloride vapor concentrations are also much lower at $2000^{\circ} \mathrm{F}$ in an oxygen-rich atmosphere (oxygen-to-propane ratio above 5), but when the oxygen level drops below stoichiometric, nickel is much more volatile as a chloride at $2000^{\circ} \mathrm{F}$. This implies that near flame temperatures, nickel volatilization from structural materials can be significant at this chlorine concentration. Downstream of the 

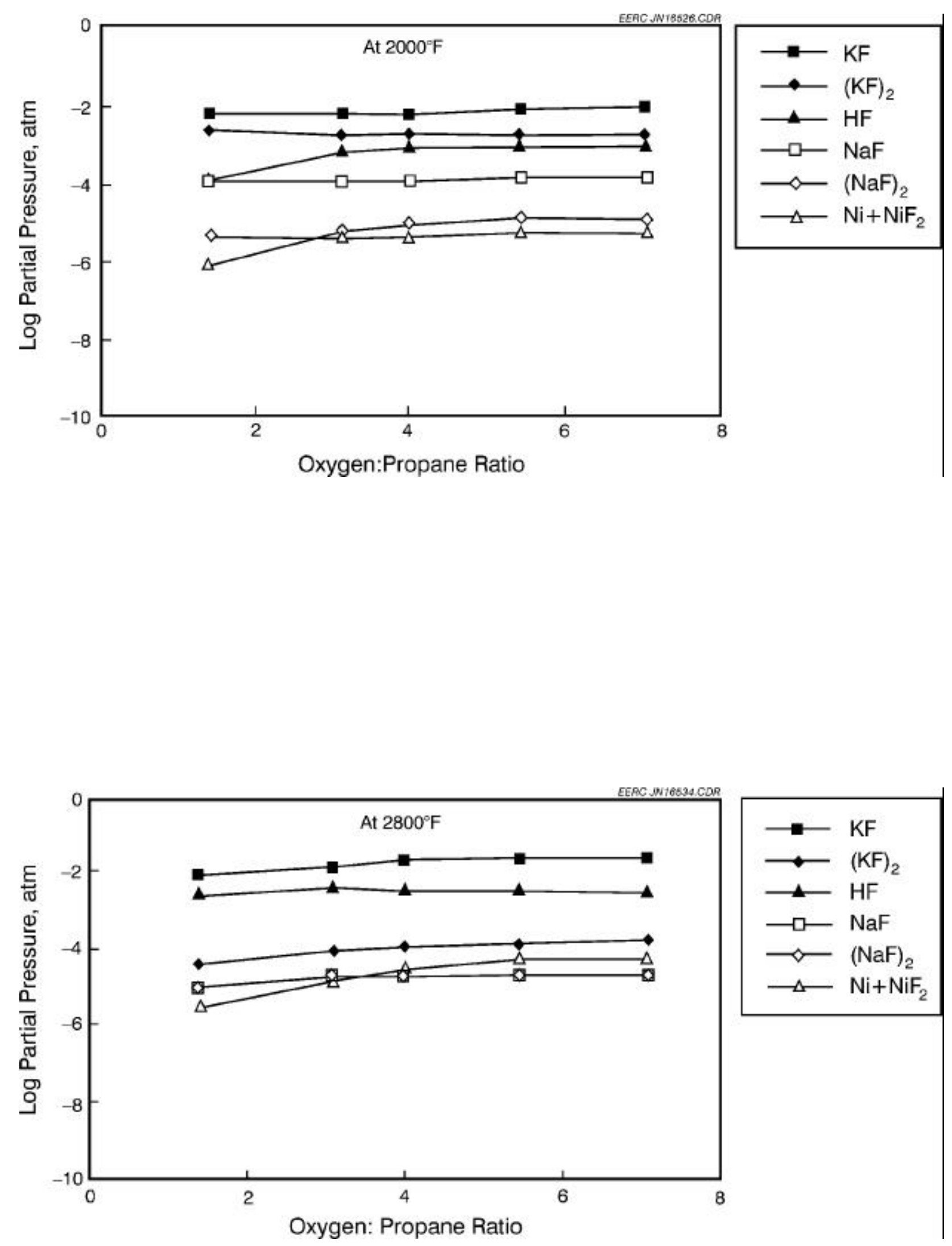

Figure 6. Composition distribution of major fluorides in the vapor phase. 

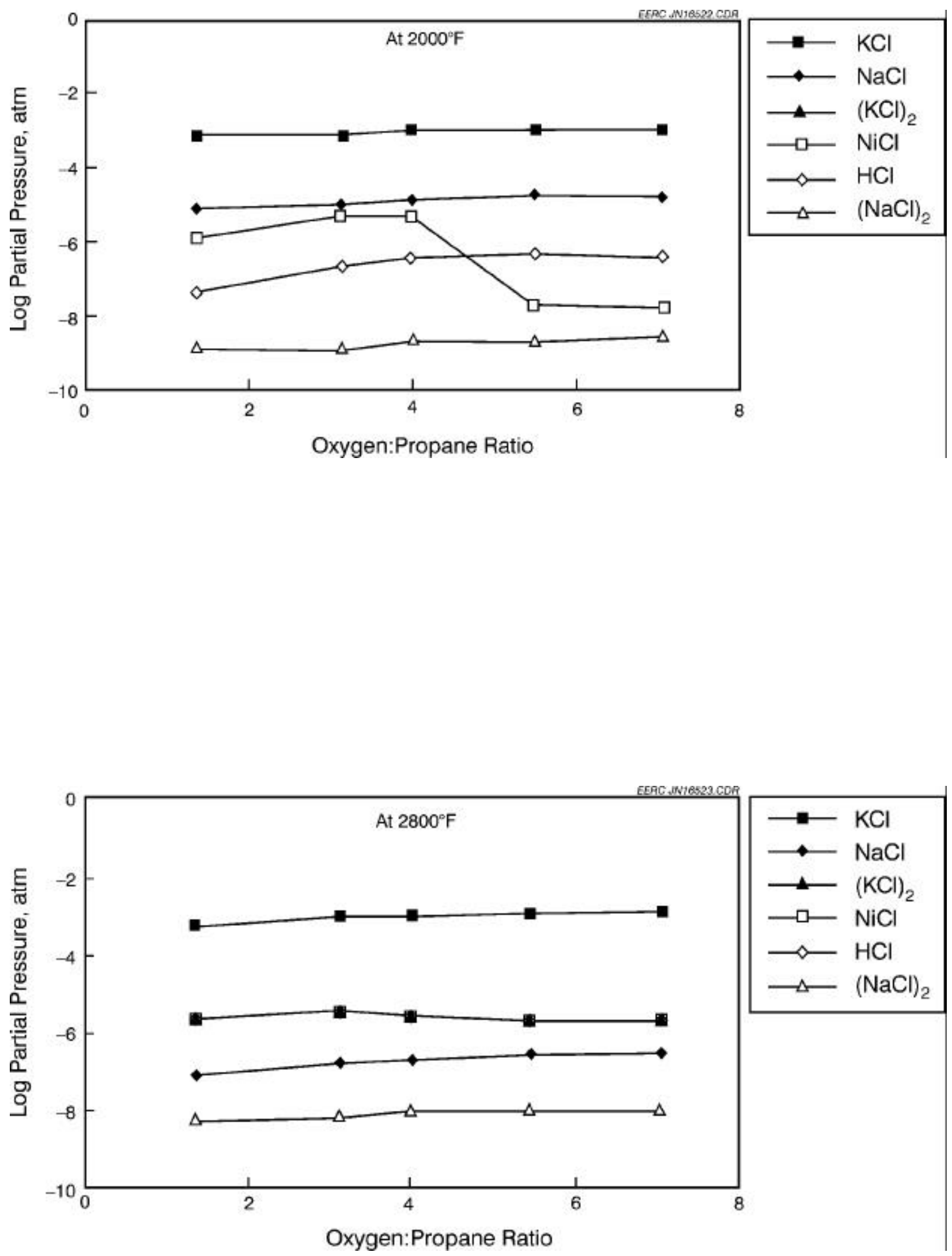

Figure 7. Composition distribution of major chlorides in the vapor phase. 

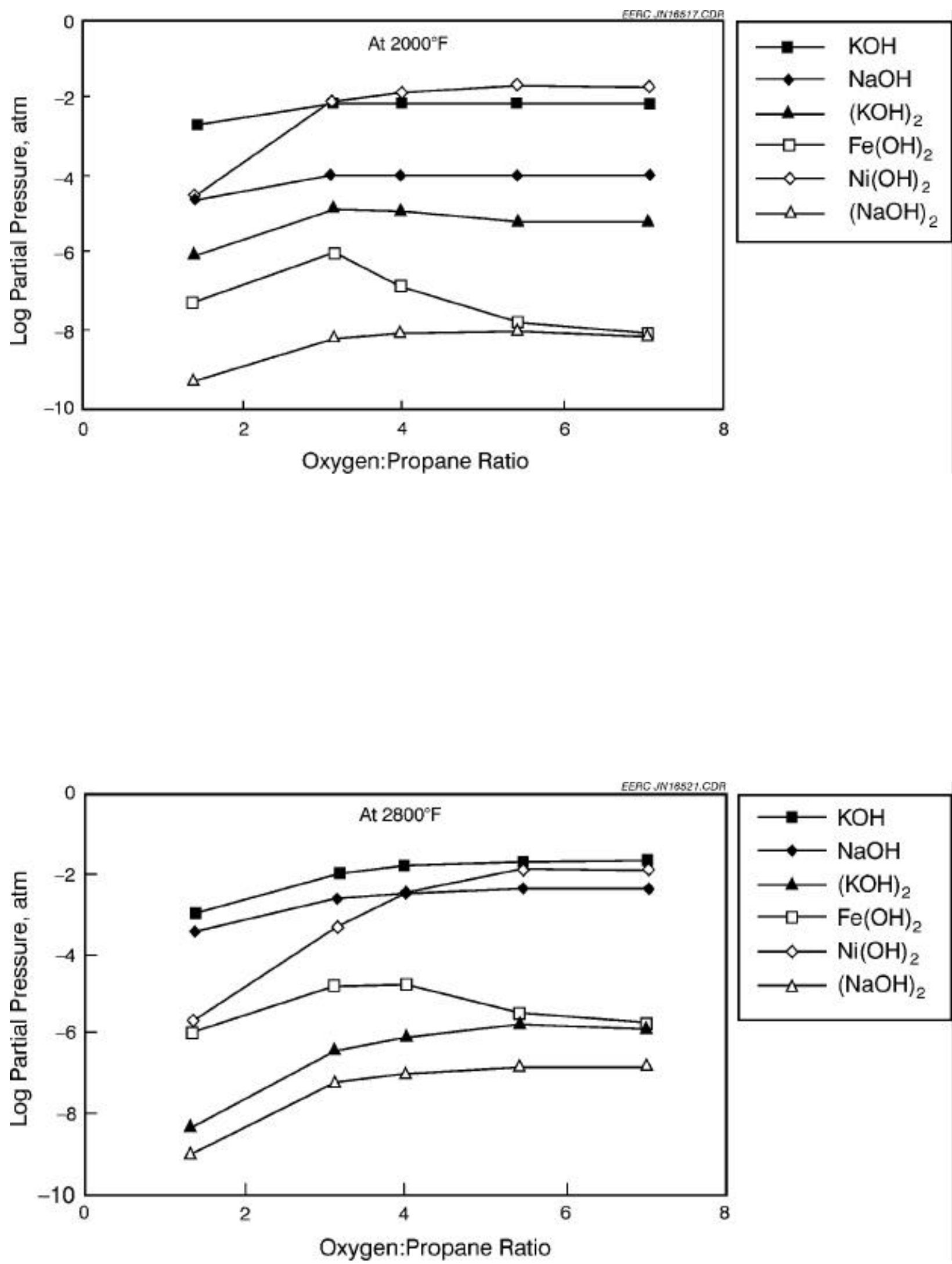

Figure 8. Composition distribution of major hydroxides in the vapor phase. 

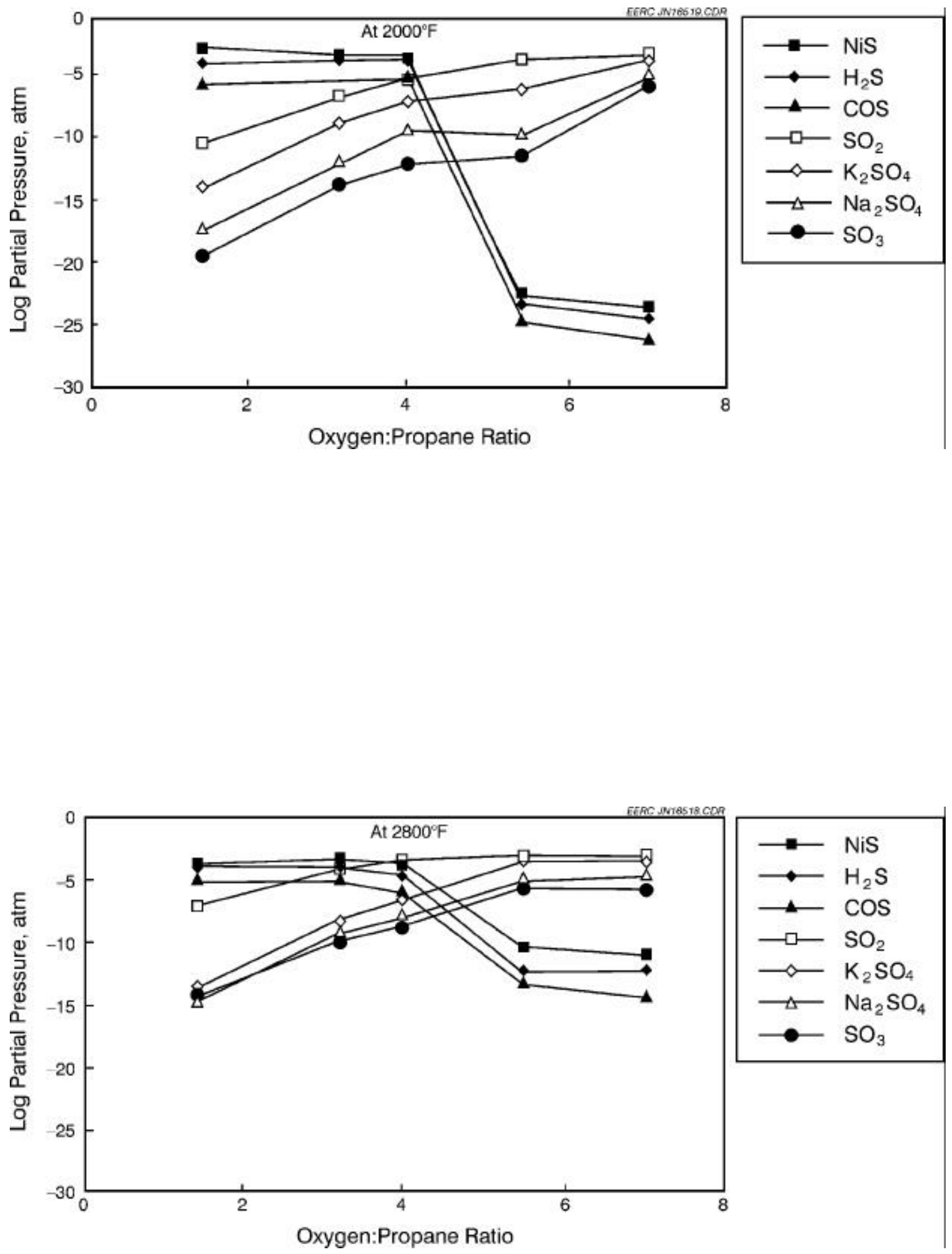

Figure 9. Composition distribution of major sulfides and sulfates in the vapor phase. 
flame, at $2000^{\circ} \mathrm{F}$, nickel vaporization is not significant except when the burner is operated in a substoichiometric fashion.

\subsubsection{Hydroxyl-Containing Species}

Figure 8 shows the calculated maximum concentrations of hydroxyl species in the gas streams. The hydroxyl radicals are formed during the combustion of the propane. The figures indicate that at $2800^{\circ} \mathrm{F}$, the hydroxides are dominated by potassium, sodium, and nickel hydroxides. In reducing conditions, the amount of nickel vaporized as a hydroxide is somewhat reduced, but potassium and sodium hydroxide concentrations remain high, and iron hydroxides become more volatile. At $2000^{\circ} \mathrm{F}$, the vapor hydroxides are dominated by potassium and nickel hydroxides at about the same concentrations they were at $2800^{\circ} \mathrm{F}$, whereas the sodium hydroxide concentration is approximately 2 orders of magnitude less. This indicates that as the vapors leave the region of the flame and begin to cool, sodium hydroxide either condenses to possibly form deposits or converts into other species.

\subsubsection{Sulfur-Containing Species}

Figure 9 shows the calculated maximum concentrations of sulfur-containing species in the gas streams. Note the expanded y-axis as compared to the previous figures. In oxidizing conditions at $2800^{\circ} \mathrm{F}$, the sulfur vapor species are dominated by sulfur dioxide, with several times less potassium sulfate vapor and about 2 orders of magnitude less sodium sulfate and sulfur trioxide. At substoichiometric oxygen-to-propane ratios, potassium and sodium sulfates and sulfur trioxide drop off rapidly to be replaced with hydrogen, nickel, and carbonyl sulfides. Sulfur dioxide drops off much more slowly and still dominates the sulfur species down to an oxygen-topropane ratio of four. At $2000^{\circ} \mathrm{F}$, the shift from sulfates to sulfides is even more dramatic since the sulfides are at much lower concentrations in oxidizing atmospheres. As Figure 5 shows, however, the total concentration of vapor-phase sulfur species does not change considerably as the oxygen-to-propane ratio changes, except right at the stoichiometric ratio at $2000^{\circ} \mathrm{F}$ where the increase in sulfides does not make up for the greater drop in sulfates, implying that at stoichiometry at $2000^{\circ} \mathrm{F}$, condensed sodium and potassium sulfate are stable and may, therefore, form deposits within the melter system. This also implies that it may be possible to remove a cap of condensed sulfate material from the surface of a melt by vaporizing it, either by increasing its temperature or by depleting or enriching the oxygen concentration in the gas above the cap.

\subsection{DISTRIBUTION OF RADIONUCLIDES IN THE EXHAUST GAS AND MELT}

\subsection{Remarks about Calculations of Radionuclide Immobilization and Vaporization}

The product of most radioactive waste vitrification systems is boro- and/or alkaline-silicate glass. The boron increases the solubility of many waste constituents in the silica-based glass while maintaining its thermal and mechanical stability. These glasses have only a slightly lower chemical durability relative to the highly durable but difficult-to-fabricate aluminosilicate glasses $(3,4)$. The concentration of radioactive waste permissible in the glass depends on its leachability in water (5). 
Redox conditions, $\mathrm{pH}$, and water chemistry play important roles in the durability of the glass. Borosilicate glass is also preferred because its amorphous structure and strong interatomic bonding allow incorporation of a wide range of waste compositions into its matrix and it can be processed at low temperatures. Ultimately, the value of a vitrification process is defined by a balance between product reliability (chemical durability, thermal stability, mechanical stability) and process reliability (system availability, fraction of product glass which is waste). The thermodynamic calculations of radionuclide vaporization and condensation behavior can be helpful in increasing process reliability by indicating possible operational parameters to avoid in order to maximize system availability and increase the concentration of the radioactive elements in the glass by reducing vaporization. However, the database of species for which calculations can be made is limited, and the behavior of species not in the database cannot be calculated. Specific species considered in the FACT calculations are shown in Table 4. In addition, the actual amount of vaporization and place of condensation are affected by factors such as reaction rates, particle size, and degree of mixing and entrainment of the elements, which cannot be estimated by the model.

\subsection{Volatilization and Condensation of Uranium Components}

The different uranium-containing species included in the FACT database are listed in Table 4. Generally, spent fuel from power reactors contains mixtures of solid uranium oxides, but two major oxides dominate: $\mathrm{UO}_{2}$ and $\mathrm{UO}_{3}$. Because of the nuclear decay processes, the intrinsic isotopic composition associated with chemical nonstoichiometry of spent uranium oxides changes over time. The oxidation state of uranium in a metastable, nonstoichiometric $\mathrm{UO}_{2+x}$ may affect its chemical responses in hydrolysis reactions and their colloid generation. It is known that the dissolution of $\mathrm{UO}_{2}$ in water, with the formation of gels, does not become significant until it is oxidized beyond the $\mathrm{UO}_{2.33}$ stage (6). In silicate melts, the oxidation states of uranium cations are either $\mathrm{U}(\mathrm{IV})$ or $\mathrm{U}(\mathrm{VI})$, and these result from the competition between energetic $(\Delta \mathrm{E}$ or $\Delta \mathrm{H})$, entropic $(\mathrm{T} \Delta \mathrm{S})$, and volumetric $(\mathrm{P} \Delta \mathrm{V})$ terms derived for stoichiometric phases (7). The nostoichiometric $\mathrm{UO}_{2+\mathrm{x}}$ phases (uraninites) may transforms into the uranium orthosilicate-coffinite, $\mathrm{USiO}_{4} \cdot \mathrm{nH}_{2} \mathrm{O}$, and it may incorporate numerous elements into its structure such as actinides $(\mathrm{Pu}, \mathrm{Am}, \mathrm{Cm})$ and fission products $(\mathrm{Zr})(8)$. The literature indicates that the initial stages of pure $\mathrm{UO}_{2}$ oxidation, i.e., $\mathrm{UO}_{2} \rightarrow \mathrm{UO}_{2+\mathrm{x}} \rightarrow \mathrm{UO}_{2.33}$, are facilitated by fission product impurities in the $\mathrm{UO}_{2}$ matrix (9). Overoxidation of uranium oxide to $\mathrm{U}_{3} \mathrm{O}_{8}$ may drastically alter the $\mathrm{UO}_{2}$ matrix, and this could increase the dissolution of silicate glass as a result of the increase of the chemical reaction rate of the fuel with water $(10,11)$. In silicate glasses, the changes of uranium oxidation state from +4 to +6 should cause a discontinuous silicate network deformation.

Figure 10 illustrates the calculated variation in partial pressures of gaseous uranium-derived components with the oxygen-to-propane ratio and temperature, assuming elemental concentrations in the feed equal to the maximum amount in any of the possible waste streams that could be processed by Vortec as shown in Table 2 and assuming chemical equilibrium conditions. Only the most concentrated dozen species are shown. The figure shows that the 
TABLE 4

Radionuclide Compounds in the FACT Database

\begin{tabular}{|c|c|c|c|}
\hline & In Vapor Phase & In Melt Phase & In Solid Phase \\
\hline Uranium & $\begin{array}{l}\mathrm{U}, \mathrm{UO}, \mathrm{UO}_{2}, \mathrm{UO}_{3}, \\
\mathrm{UOH} \mathrm{UO}_{2} \mathrm{H}_{2}, \\
\mathrm{UO}_{3}\left(\mathrm{H}_{2} \mathrm{O}\right), \mathrm{UF}, \mathrm{UF}_{2}, \\
\mathrm{UF}_{3}, \mathrm{UF}_{4}, \mathrm{UF}_{5}, \mathrm{UF}_{6}, \\
\mathrm{U}_{2} \mathrm{~F}_{10}, \mathrm{UOF}, \mathrm{UO}_{2} \mathrm{~F}, \\
\mathrm{UOF}_{2}, \mathrm{UO}_{2} \mathrm{~F}_{2}, \mathrm{UOF}_{3}, \\
\mathrm{UOF}_{4}, \mathrm{UCl}_{3}, \mathrm{UCl}_{4}, \\
\mathrm{UCl}_{5}, \mathrm{UCl}_{6}, \mathrm{UO}_{2} \mathrm{Cl}_{2}\end{array}$ & $\begin{array}{l}\mathrm{U}, \mathrm{UF}_{4}, \mathrm{UF}_{5}, \mathrm{UF}_{6} \\
\mathrm{UCl}_{3}, \mathrm{UCl}_{4}, \mathrm{UCl}_{5} \\
\mathrm{UCl}_{6}, \mathrm{UOCl}, \mathrm{UFe}_{2}\end{array}$ & $\begin{array}{l}\mathrm{U}, \mathrm{UH}_{3}, \mathrm{UO}_{2}, \mathrm{UO}_{3}, \\
\mathrm{U}_{3} \mathrm{O}_{8}, \mathrm{U}_{4} \mathrm{O}_{9}, \\
\mathrm{UO}_{3}\left(\mathrm{H}_{2} \mathrm{O}\right), \\
\mathrm{UO}_{3}\left(\mathrm{H}_{2} \mathrm{O}\right)_{2}, \mathrm{UF}_{3}, \\
\mathrm{UF}_{4}, \mathrm{UF}_{5}, \mathrm{UF}_{6}, \mathrm{U}_{2} \mathrm{~F}_{9}, \\
\mathrm{U}_{4} \mathrm{~F}_{17}, \mathrm{UO}_{2} \mathrm{~F}_{2}, \mathrm{UOF}_{2}, \\
\mathrm{Na}_{3} \mathrm{UO}_{4}, \mathrm{USi}, \mathrm{USi}_{2}, \\
\mathrm{USi}_{3}, \mathrm{U}_{3} \mathrm{Si}_{3} \mathrm{U}_{3} \mathrm{Si}_{2}, \\
\mathrm{U}_{3} \mathrm{Si}_{5}, \mathrm{UCl}_{3}, \mathrm{UCl}_{4}, \\
\mathrm{UCl}_{5} \mathrm{UCl}_{6}, \mathrm{UOCl}, \\
\mathrm{UOCl}_{2}, \mathrm{UO}_{2} \mathrm{Cl}_{2}, \\
\mathrm{UOCl}_{3}, \mathrm{UFe}_{2}\end{array}$ \\
\hline Plutonium & $\begin{array}{l}\mathrm{Pu}, \mathrm{PuO}, \mathrm{PuO}_{2} \\
\mathrm{PuO}_{3}, \mathrm{PuO}_{3}\left(\mathrm{H}_{2} \mathrm{O}\right), \\
\mathrm{PuO}_{2} \mathrm{~F}_{2}, \mathrm{PuCl}_{3}, \mathrm{PuCl}_{4}, \\
\mathrm{PuO}_{2} \mathrm{Cl}_{2}\end{array}$ & $\begin{array}{l}\mathrm{Pu}, \mathrm{PuO}_{2}, \mathrm{PuF}_{3}, \\
\mathrm{PuF}_{4}, \mathrm{PuF}_{6}, \mathrm{PuCl}_{3}, \\
\mathrm{PuCl}_{4}, \mathrm{PuOCl}\end{array}$ & $\begin{array}{l}\mathrm{Pu}, \mathrm{PuH}_{2}, \mathrm{PuH}_{3}, \\
\mathrm{PuO}_{2}, \mathrm{Pu}_{2} \mathrm{O}_{3}, \mathrm{Pu}_{5} \mathrm{O}_{8}, \\
\mathrm{PuF}_{3}, \mathrm{PuF}_{4}, \mathrm{PuF}_{6}, \\
\mathrm{PuOF} \mathrm{PuCl}_{3}, \mathrm{PuCl}_{4}, \\
\mathrm{PuOCl}\end{array}$ \\
\hline Thorium & $\begin{array}{l}\mathrm{ThO}, \mathrm{ThO}_{2}, \mathrm{ThF}_{4} \text {, } \\
\mathrm{ThCl}_{4}\end{array}$ & $\begin{array}{l}\mathrm{Th}, \mathrm{ThO}_{2}, \mathrm{ThF}_{4} \text {, } \\
\mathrm{ThCl}_{4}\end{array}$ & $\begin{array}{l}\text { Th, } \mathrm{ThH}_{2}, \mathrm{ThO}_{2}, \\
\mathrm{ThF}_{4}, \mathrm{ThOF}_{2}, \mathrm{ThMg}_{2} \text {, } \\
\mathrm{ThSi}_{\mathrm{ThSi}}, \mathrm{Th}_{3} \mathrm{Si}_{2}, \\
\mathrm{Th}_{3} \mathrm{Si}_{5}, \mathrm{ThP}, \mathrm{Th}_{3} \mathrm{P}_{4}, \\
\mathrm{ThCl}_{2}, \mathrm{ThCl}_{3}, \mathrm{ThCl}_{4} \text {, } \\
\mathrm{ThOCl}_{2}\end{array}$ \\
\hline Neptunium & $\mathrm{NpF}_{6}$ & None & $\begin{array}{l}\mathrm{Np}, \mathrm{NpO}_{2}, \\
\mathrm{NpO}_{3}\left(\mathrm{H}_{2} \mathrm{O}\right), \mathrm{NpF}_{3}, \\
\mathrm{NpCl}_{3}, \mathrm{NpCl}_{4}, \\
\mathrm{NpOCl}_{2}\end{array}$ \\
\hline Technetium & $\begin{array}{l}\mathrm{Tc}, \mathrm{TcO}, \mathrm{TcO}_{2}, \\
\mathrm{TcOH}, \mathrm{TcO}_{2} \mathrm{H}_{2}\end{array}$ & $\mathrm{Tc}, \mathrm{Tc}_{2} \mathrm{O}_{7}$ & $\begin{array}{l}\mathrm{Tc}, \mathrm{TcO}_{2}, \mathrm{TcO}_{3}, \\
\mathrm{Tc}_{2} \mathrm{O}_{7}\end{array}$ \\
\hline Cesium & $\begin{array}{l}\mathrm{Cs}, \mathrm{Cs}_{2}, \mathrm{CsH}, \mathrm{CsO}, \\
\mathrm{Cs}_{2} \mathrm{O}, \mathrm{Cs}_{2} \mathrm{O}_{2}, \mathrm{CsOH}, \\
(\mathrm{CsOH})_{2}, \mathrm{CsF}, \\
(\mathrm{CsF})_{2}, \mathrm{CsCl},(\mathrm{CsCl})_{2}, \\
\mathrm{Cs}_{2} \mathrm{CrO}_{4}\end{array}$ & $\begin{array}{l}\mathrm{Cs}, \mathrm{CsOH}, \mathrm{CsF}, \\
\mathrm{CsCl}, \mathrm{Cs}_{2} \mathrm{CrO}_{4}, \\
\mathrm{Cs}_{2} \mathrm{Cr}_{2} \mathrm{O}_{7}\end{array}$ & $\begin{array}{l}\mathrm{Cs}, \mathrm{CsO}_{2}, \mathrm{Cs}_{2} \mathrm{O}, \\
\mathrm{Cs}_{2} \mathrm{O}_{3}, \mathrm{CsOH}, \mathrm{CsF}, \\
\mathrm{CsCl} \mathrm{Cs}_{2} \mathrm{CrO}_{4}, \\
\mathrm{Cs}_{2} \mathrm{Cr}_{2} \mathrm{O}_{7}, \mathrm{Cs}_{3} \mathrm{CrO}_{4}\end{array}$ \\
\hline
\end{tabular}



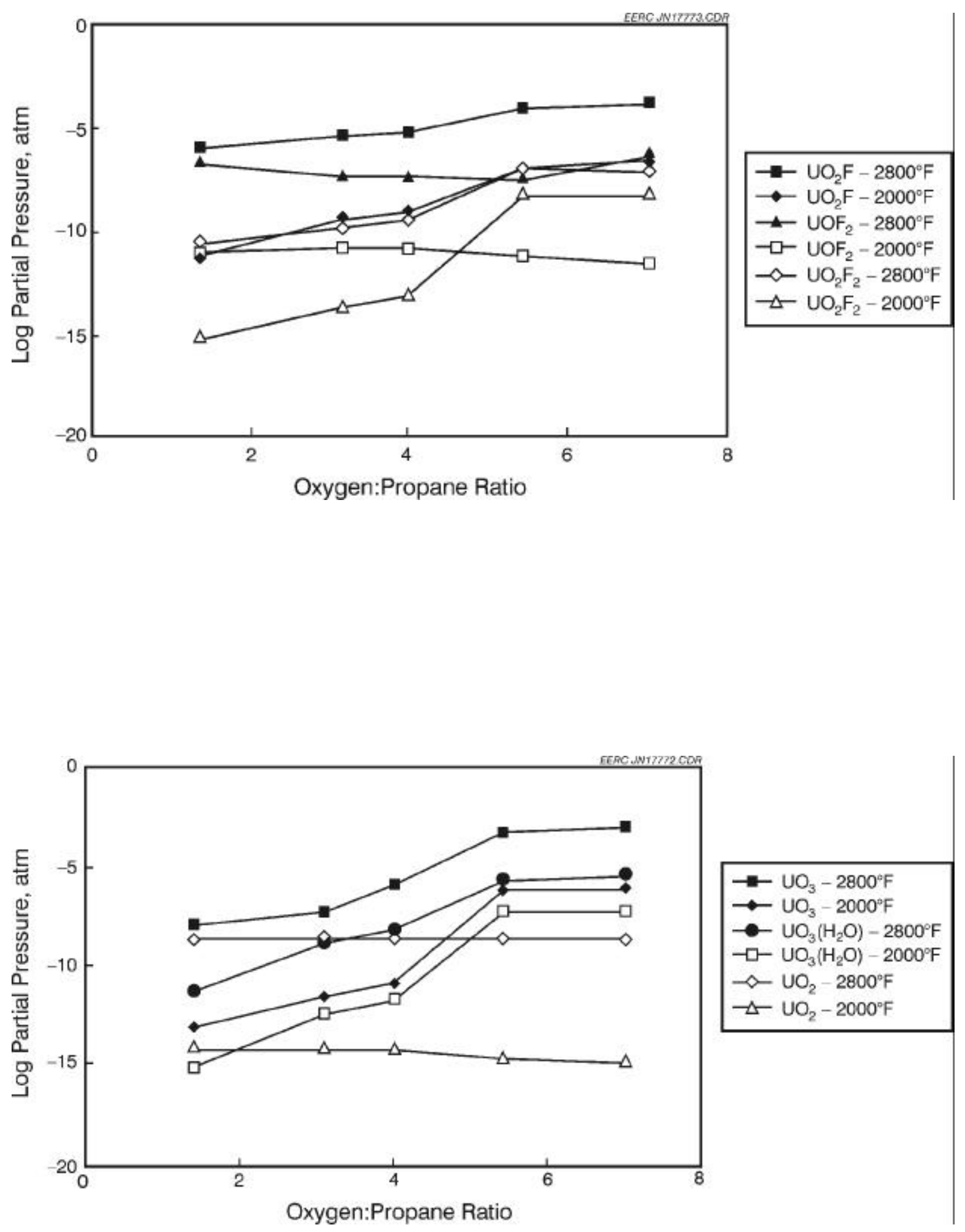

Figure 10. Distribution of uranium-derived components in the vapor phase as functions of flame stoichiometry at $2000^{\circ}$ and $2800^{\circ} \mathrm{F}$. 
primary uranium vapor species are oxides and oxyfluorides. Uranium chloride vapors are predicted to be present at much lower concentrations, indicating that chlorine does not play a significant role in vaporizing the uranium. The majority of the vapor uranium is $\mathrm{UO}_{3}$, followed by $\mathrm{UO}_{2} \mathrm{~F}$, indicating that small changes in fluorine contents in the feed material will not dramatically affect the amount of uranium vaporization, although large increases could increase uranium vaporization. Over $99 \%$ of the vaporized uranium can be expected to condense by the time the gas cools to $2000^{\circ} \mathrm{F}$. This implies that the system design should provide for removing deposits formed between the flame and the point in the system where the gas reaches this temperature. In particular, the design should allow for knocking deposits off walls or heat exchange surfaces such that the deposit falls into the melt material. Once in the melt, the larger deposit pieces would be slow to vaporize and could be removed from the system with the glass either by dissolving in the glass or being encapsulated by it.

As the oxygen-to-propane ratio in the flame increases, vaporization also increases. Generally, the largest increase in uranium vaporization occurs if the oxygen-to-propane ratio increases above 4 (stoichiometric flame $=5$ ) and is more pronounced at the higher temperature. This indicates that if uranium vaporization is a problem in the system, decreasing the oxygen-topropane ratio; may have a significant effect at reducing the vaporization, although carbon monoxide production then becomes an issue. Figure 11 shows the percentage of total uranium that is calculated to be vaporized at equilibrium as a function of temperature and oxygen-topropane ratio, the remaining mole \% (100 - vapor) is solid. The figure shows that up to $4 \%$ of the uranium could exist as vapor in a stoichiometric flame at equilibrium and up to $7 \%$ in fuel-lean conditions. Under the reducing conditions of an oxygen-to-propane ratio of 4 , however, the amount that could vaporize is reduced by $99 \%$ as compared to that vaporized in a stoichiometric flame. Additional calculations show that generally the calculated concentration of uranium in the vapor at equilibrium decreases by approximately 1 order of magnitude for every $220^{\circ} \mathrm{F}$ drop in temperature down to $2000^{\circ} \mathrm{F}$. This indicates that there is not a specific critical temperature that must be avoided to prevent vaporization, but that vaporization does drop rapidly with temperature.

\subsection{Volatilization of Plutonium Components}

The different plutonium-containing species included in the FACT database are listed in Table 4. From an environmental standpoint, four long-lived plutonium isotopes are important:

${ }^{238} \mathrm{Pu}$ (half-life 88 years), ${ }^{239} \mathrm{Pu}\left(24,000\right.$ years), ${ }^{240} \mathrm{Pu}\left(6400\right.$ years), and ${ }^{241} \mathrm{Pu}$ (14 years). Figure 12 illustrates the variation of maximum log partial pressures of plutonium-derived vapor components with temperature. The thermodynamic calculations were performed for slightly reducing conditions with $\mathrm{O}_{2}$-propane $=4.00$ and under slightly oxidizing with $\mathrm{O}_{2}$-propane $=5.44$. Generally, the concentration of plutonium in the vapor is expected to be much lower than that of uranium, primarily because even at its highest expected concentration in the Vortec wastes there is less than one-millionth as much plutonium as uranium (Table 3). Because of its low concentration in the feed, at $2800^{\circ} \mathrm{F}$ there is less than a part per billion concentration in the flame. As was true for uranium, the plutonium vaporization decreases under slightly reducing conditions, although there is almost no effect at $2800^{\circ} \mathrm{F}$. The biggest effects of flame stoichiometry occur at lower temperatures where several orders of magnitude more plutonium 

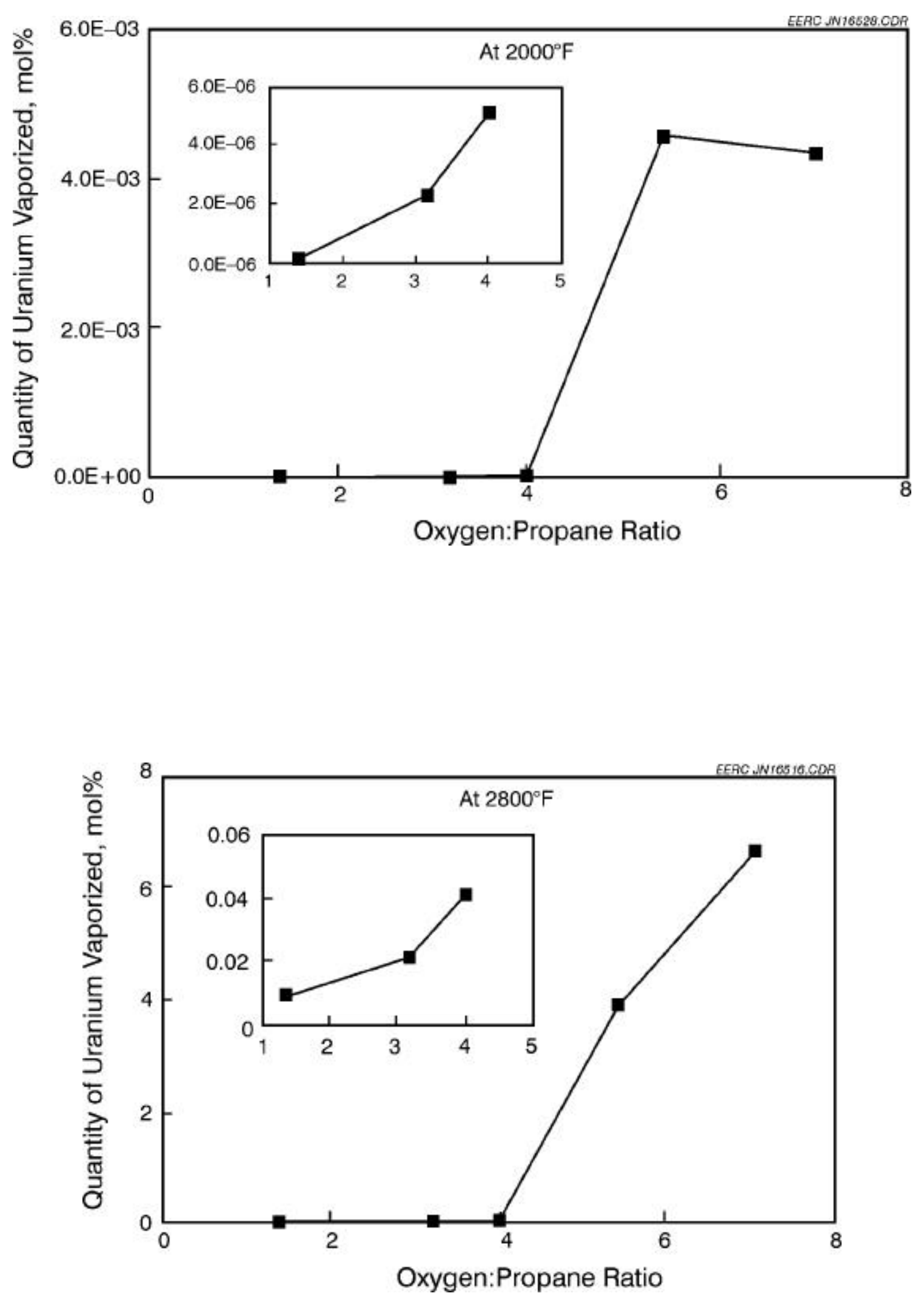

Figure 11. Effect of temperature and flame stoichiometry on uranium vaporization (mol\%). 

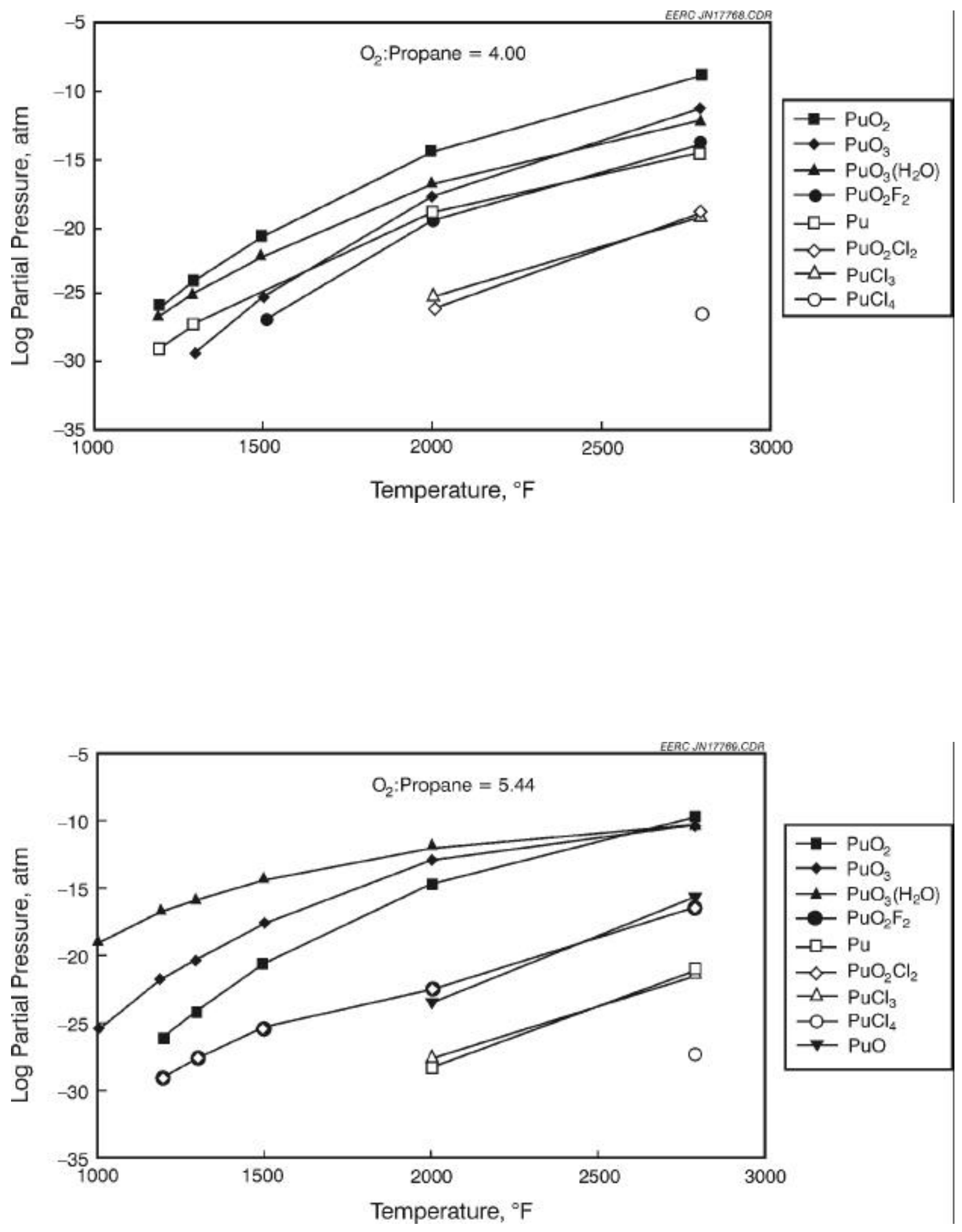

Figure 12. Concentrations of different vapor-phase plutonium species as functions of flame stoichiometry at $2000^{\circ}$ and $2800^{\circ} \mathrm{F}$. 
could be present in the vapor under oxidizing conditions than under reducing. However, the concentrations at lower temperatures are in the part per trillion to part per quadrillion level. The primary reduction comes in the concentrations of $\mathrm{PuO}_{3}$ and $\mathrm{PuO}_{3}\left(\mathrm{H}_{2} \mathrm{O}\right)$, whereas $\mathrm{PuO}_{2}$ vaporization is little affected by flame stoichiometry. As was also true for uranium, there is no critical temperature for this system where plutonium vaporization jumps significantly. Instead, like uranium, its log partial pressure decreases directly with temperature, indicating that the vaporization drops rapidly, but in a smooth fashion, with temperature drop.

Figure 12 also shows that hydroxide, fluorine, and chlorine concentrations in the feedstocks have little influence on plutonium vaporization. In part, this is because they are bound in other forms, especially as sodium, potassium, and hydrogen compounds. Even if the alkali metal concentrations were decreased significantly, the hydrogen forms of these species are much more stable than the plutonium forms. Therefore, as long as a fossil fuel flame is used to heat the Vortec melter, then there will be an excess of water vapor present, and plutonium vaporization as a fluoride, chloride, or hydroxide is predicted to be less than a tenth of a ppb. However, in systems where little water vapor is present and if the alkali metal concentration in the feedstock is less than the amount necessary to absorb the halogens and hydroxide, then the vaporization of plutonium as fluorides, chlorides, or hydroxides could become more significant.

In addition to calculating the concentrations of different chemical species in the vapor phase, the thermodynamic equilibrium modeling can also be used to calculate the relative vaporization of the radionuclides at equilibrium. Figure 13 shows the quantity of plutonium that vaporizes, in mole \%, as a function of temperature for the oxygen-to-propane ratios of 4 and 5.44. The graph shows that because of the low maximum concentration of plutonium in the materials to be processed by Vortec, $100 \%$ of it could conceivably vaporize at a flame temperature of $2800^{\circ} \mathrm{F}$. This vaporized plutonium would be expected to essentially completely condense as the gas cooled to $2000^{\circ} \mathrm{F}$, possibly even within the melter. A similar conclusion was derived by Krikorian et al. from their experimental work on the volatilization of plutonium oxides in the presence of steam and oxygen (12). Figure 14 shows the relative split in plutonium between the condensed and vapor phases in the flame at $2800^{\circ} \mathrm{F}$ as functions of the plutonium in the waste material and the flame stoichiometry. The data indicate that if the plutonium concentration is less than approximately one part per million in the waste, then most of it will volatilize. At concentrations above a part per million, the gas stream is saturated and the remainder goes into the glass. However, the assumes equilibrium conditions. Depending on the association of the plutonium in the waste material, equilibrium probably will not be achieved, so that in actual practice, less plutonium will vaporize than predicted, and more will go into the glass product than the predictions indicate. The most thermodynamically stable solid oxide phase is $\mathrm{PuO}_{2}$, and its chemical stability is independent of the reducing/oxidizing conditions of the propane-air flame.

\subsection{Volatilization of Thorium and Neptunium Components}

The thorium- and neptunium-containing species included in the FACT database are listed in Table 4. Figure 15 illustrates the percentage of the thorium that should vaporize at equilibrium as a function of temperature and flame stoichiometry: less than three one-thousandths of a 


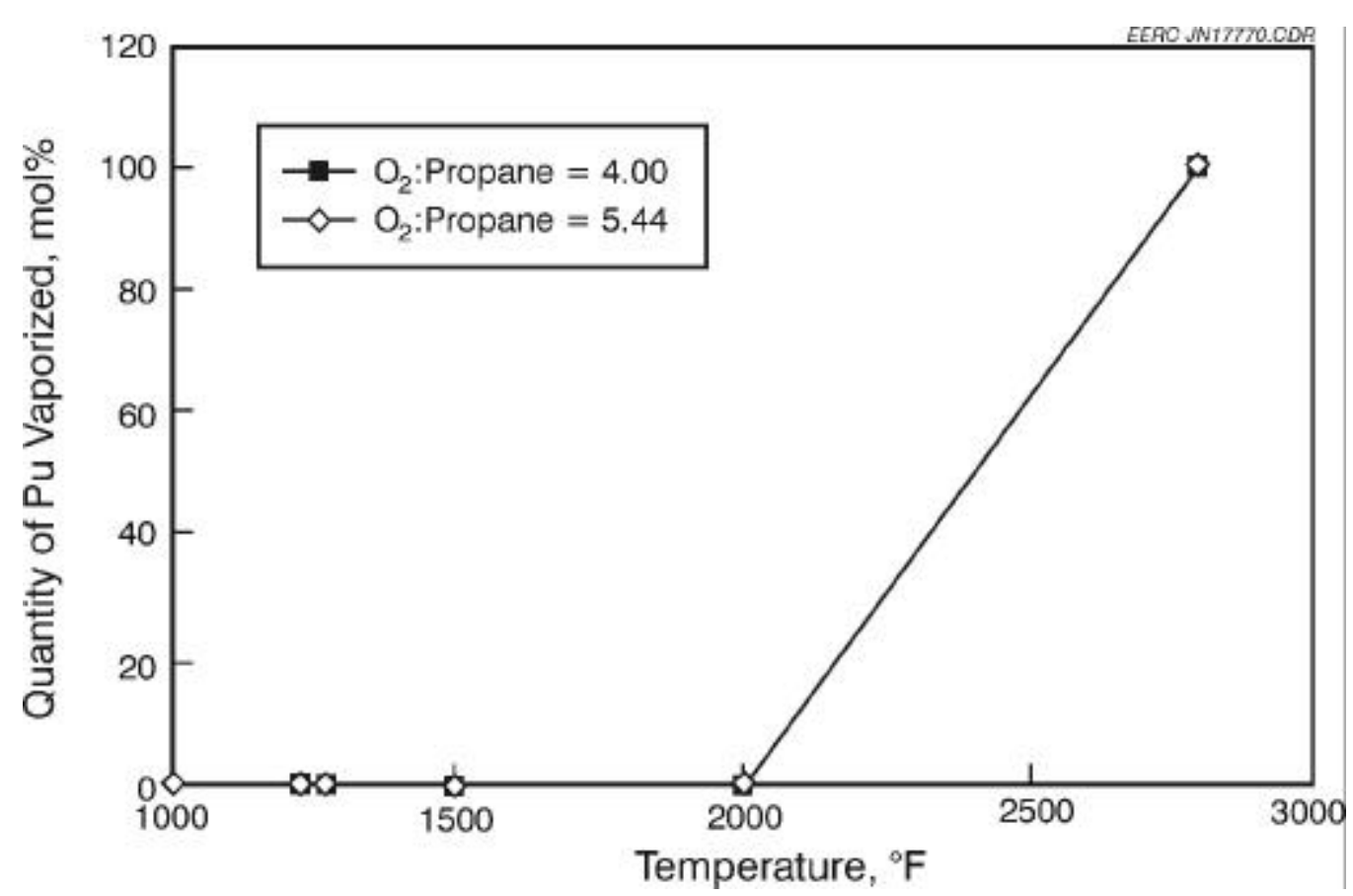

Figure 13. Percentage of plutonium in the vapor phase as functions of flame stoichiometry and temperature.

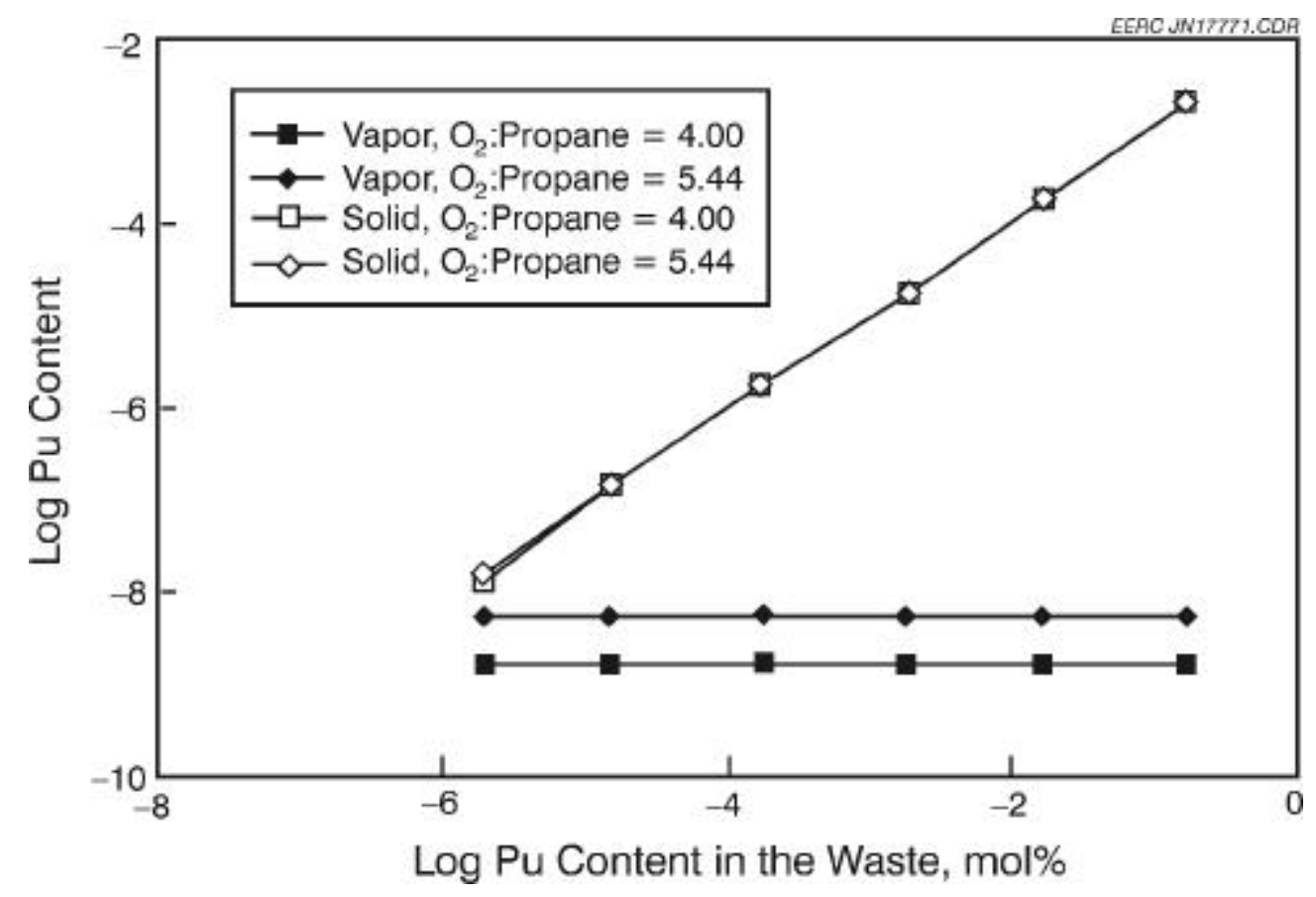

Figure 14. Percentage of $\mathrm{Pu}$ in the vapor and solid phases at $2800^{\circ} \mathrm{F}$ as functions of the concentration of plutonium in the waste material and the flame stoichiometry. 

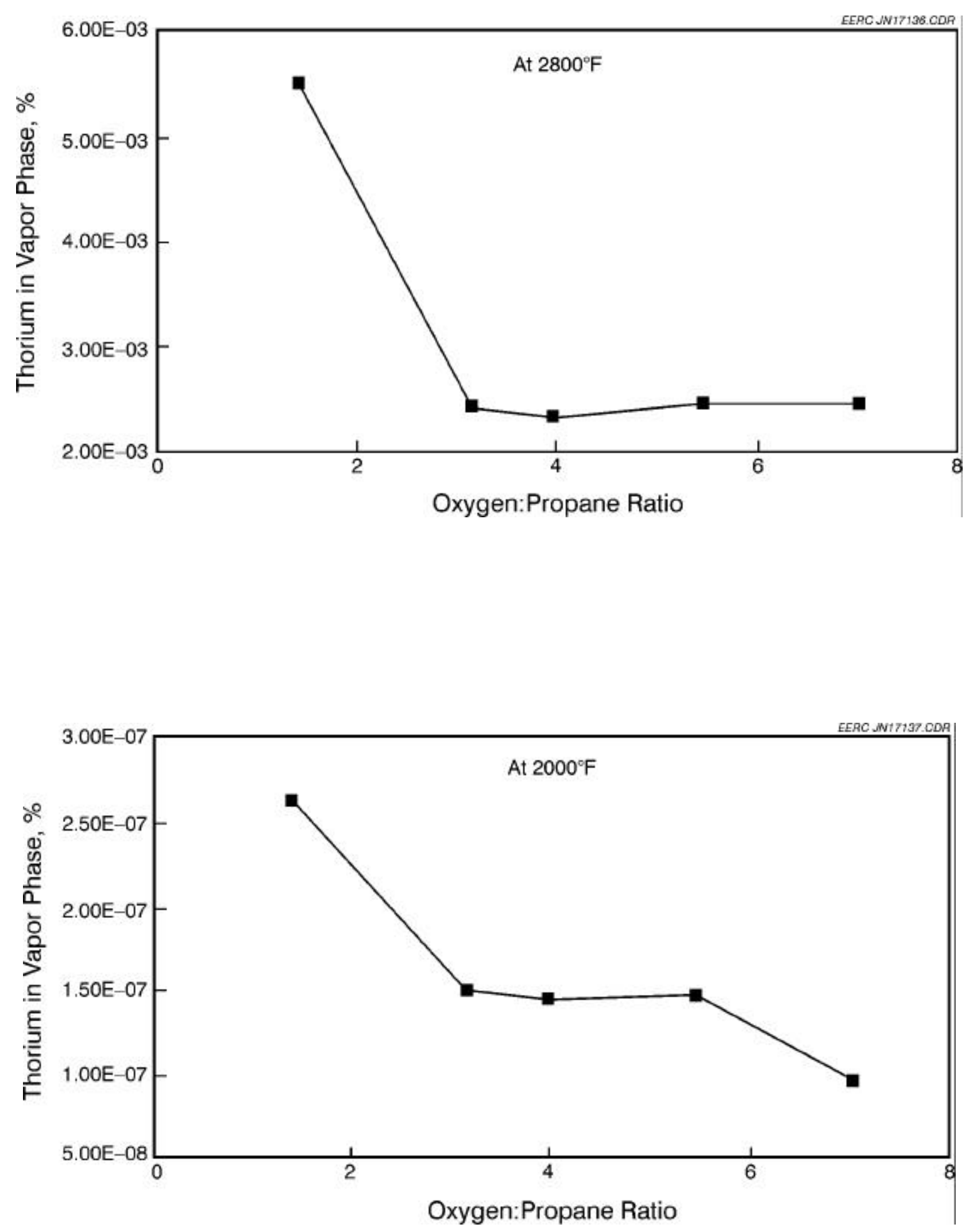

Figure 15. Mole percentage of thorium that vaporizes at equilibrium as functions of flame stoichiometry at $2000^{\circ}$ and $2800^{\circ} \mathrm{F}$. 
percent, 4 orders of magnitude less than that at $2000^{\circ} \mathrm{F}$. The amount is essentially independent of oxygen-to-propane ratios, only doubling when going to unrealistically low levels. Figure 16 shows the gas stream concentrations of major vapor species. The most dominant vapor components are $\mathrm{ThF}_{4}$ and $\mathrm{ThO}_{2}$. Increasing fluorine contents will increase the amount of thorium vaporization, but unless levels become exceptionally high, the level of thorium vaporization will remain very low. In the solid phase, $\mathrm{ThO}_{2}$ dominates. In silicate glasses, thorium is primarily six $\left(\mathrm{ThO}_{6}\right)$ - and eight $\left(\mathrm{ThO}_{8}\right.$ )-coordinated up to the maximum thorium solubility (about $3 \mathrm{wt} \%$ ). At very low thorium concentrations (about $100 \mathrm{ppm}$ ), a larger fraction is eight-coordinated (8).

Similar calculations performed for neptunium components has shown that the solid crystalline $\mathrm{NpO}_{2}$ phase is the only stable phase formed below $2800^{\circ} \mathrm{F}$. However, because of the lack of data for vapor species of neptunium as shown in Table 4, the calculations with the present database for vaporization of the element are not conclusive.

\subsection{Volatilization of Technetium Components}

The different technetium-containing species included in the FACT database are listed in Table 4. Technetium is a hazardous fission product with a half-life of 200,000 years. In the vitrification of nuclear waste, technetium oxides are known to be lost substantially by vaporization, especially under normal oxidizing conditions (13). The highest oxidation state of Tc is 7, such as in $\mathrm{Tc}_{2} \mathrm{O}_{7}$. The melting point of $\mathrm{Tc}_{2} \mathrm{O}_{7}$ is $247^{\circ} \mathrm{F}(392.6 \mathrm{~K})$. Reducing conditions lead to the formation of $\mathrm{TcO}_{2}$, which precipitates from the melt. Stronger reducing conditions lead to the formation of metallic Tc (14).

Figure 17 illustrates the calculated maximum equilibrium concentrations of technetium species in the Vortec melter vapor during the initial 30-day test as functions of temperature and flame stoichiometry. As was true for plutonium, the very low maximum concentration of technetium in the Vortec wastes and the high volatility of the technetium causes all of the technetium to vaporize under equilibrium conditions. However, if the feed material is composed of larger pieces and the glass is quickly removed from the melter, there may not be sufficient time for all of the technetium to volatilize. Almost all of the technetium is condensed at $2000^{\circ} \mathrm{F}$ at equilibrium, leaving less than $1 \%$ of the original amount in the vapor phase. The vaporized technetium is dominated by $\mathrm{TcO}_{2}$ under oxidizing conditions, but the concentration of $\mathrm{TcO}$ becomes nearly as great under reducing conditions. Possible chlorine and fluorine species could not be determined because they are not available in the FACT database as indicated in Table 4. As is true for the vapor, $\mathrm{TcO}_{2}$ dominates the condensed phases, especially at higher oxygen partial pressures. However, in order for condensed technetium to be present at equilibrium at $2800^{\circ} \mathrm{F}$, the concentration of technetium in the feed must be approximately 2 orders of magnitude greater than the maximum expected in the Vortec feed materials to be used in the initial 30-day test.

\subsection{Volatilization of Cesium Components}

Cesium $\left({ }^{137} \mathrm{Cs}\right.$ and $\left.{ }^{134} \mathrm{Cs}\right)$ is very likely to volatilize during vitrification in a glass (15). It is usually removed from high-level tank wastes by an ion-exchange process using crystalline 

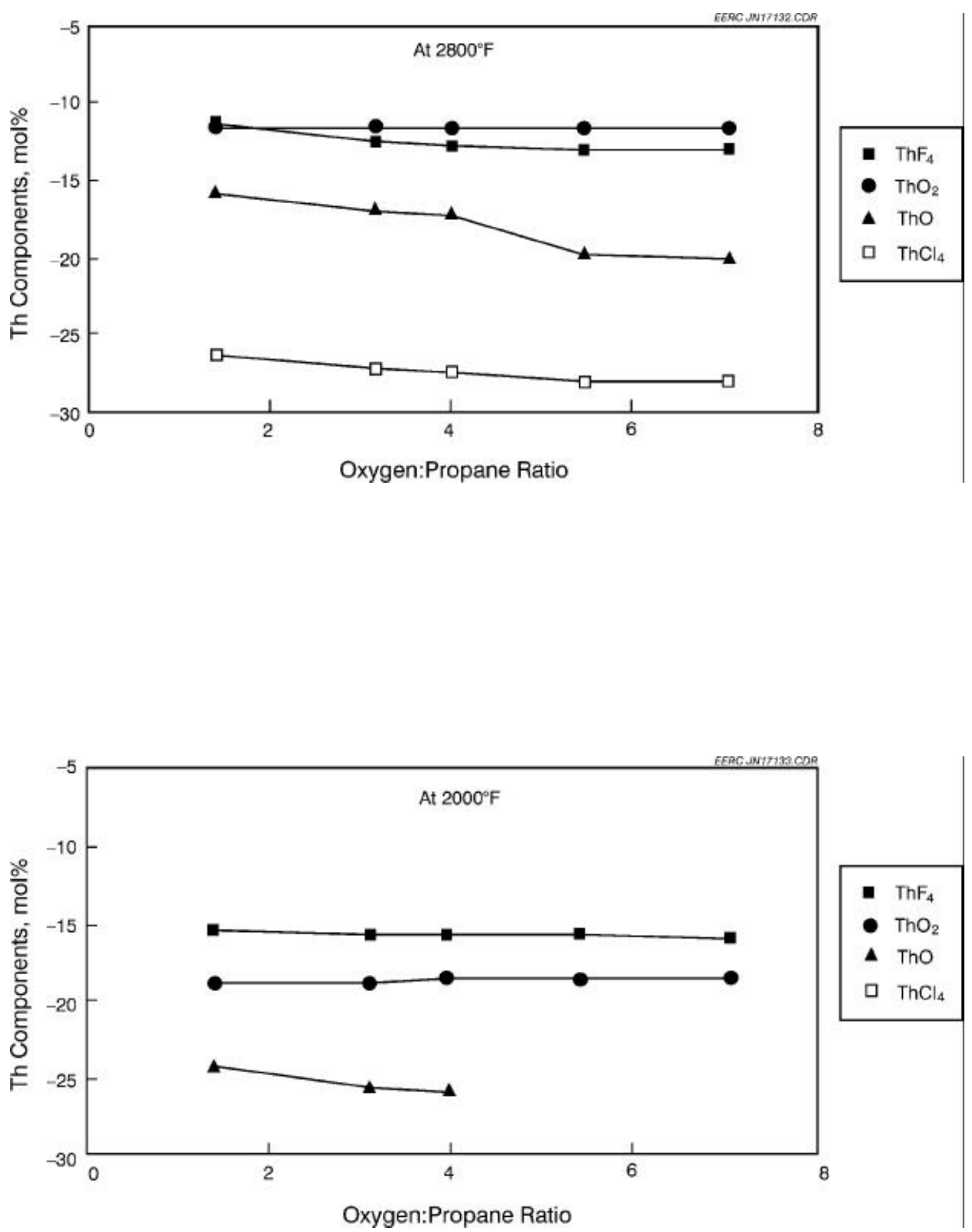

Figure 16. Concentrations of different vapor-phase thorium species as functions of flame stoichiometry at $2000^{\circ}$ and $2800^{\circ} \mathrm{F}$. 


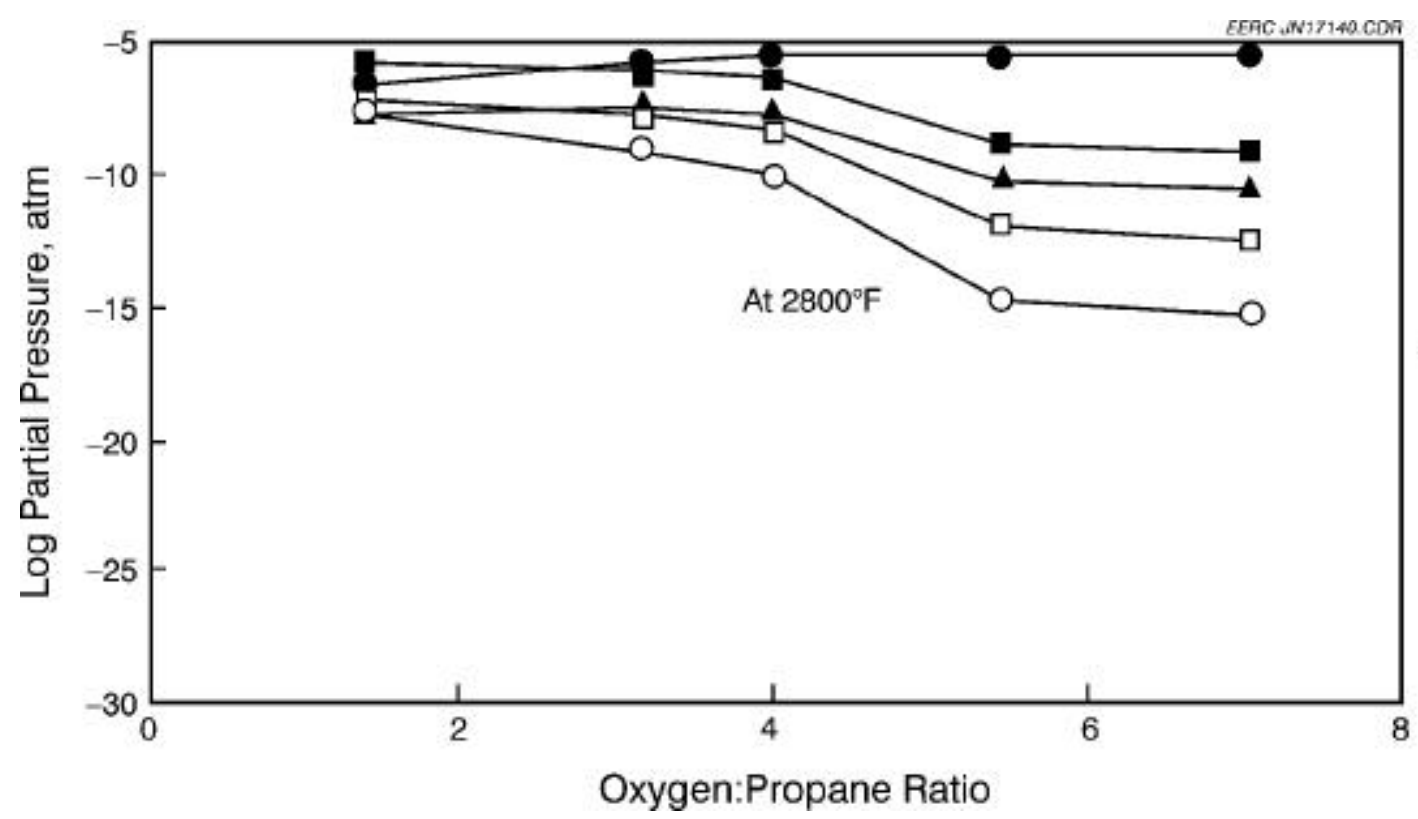

$\mathrm{TCO}$

- $\mathrm{TCO}_{2}$

- $\mathrm{TCO}_{2} \mathrm{H}_{2}$

․ $\mathrm{TCOH}$

O TC

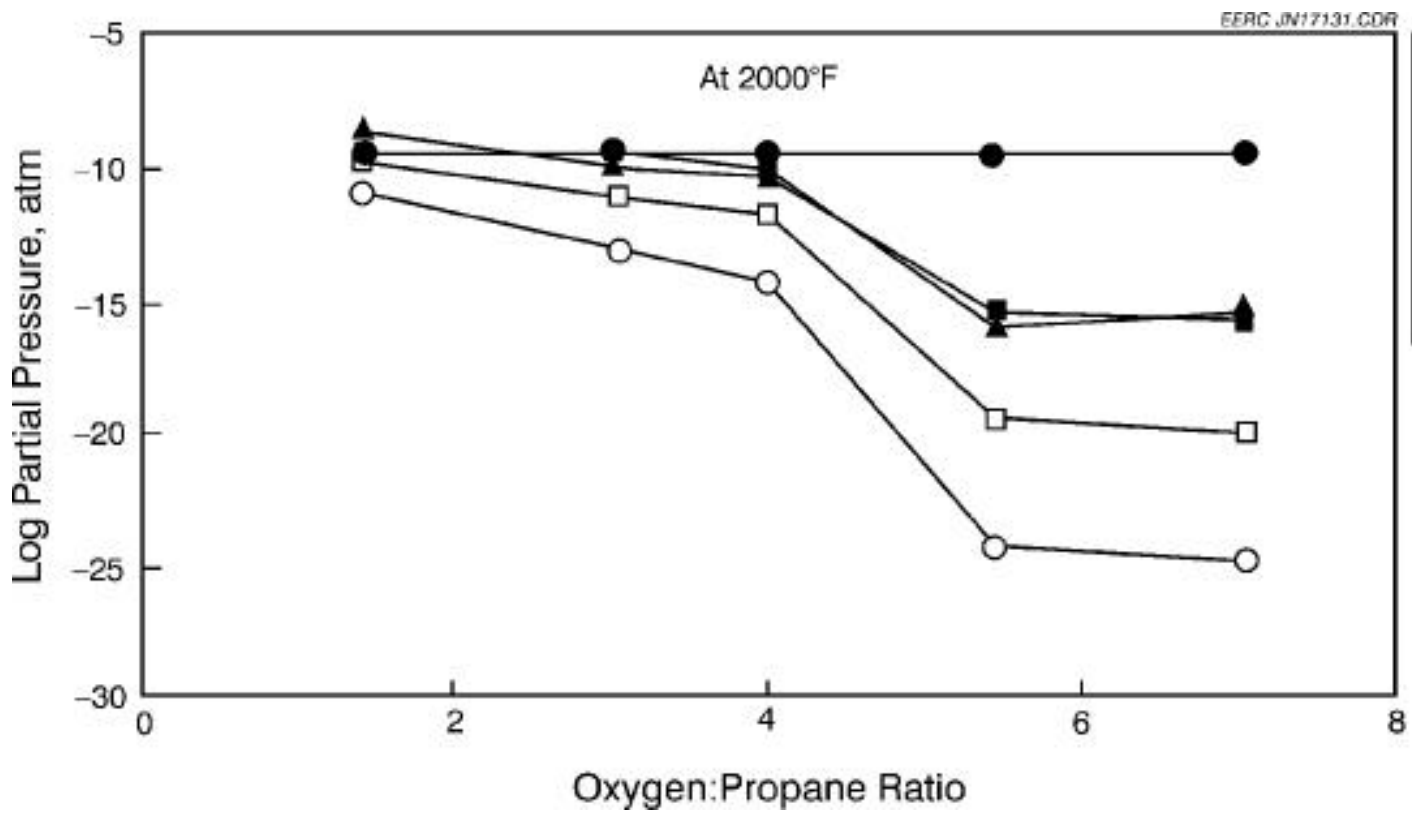

- $\mathrm{TCO}$

- $\mathrm{TcO}_{2}$

A $\mathrm{TcO}_{2} \mathrm{H}_{2}$

$\square \mathrm{TCOH}$

O TC

Figure 17. Concentrations of different vapor-phase technetium species as functions of flame stoichiometry at $2000^{\circ}$ and $2800^{\circ} \mathrm{F}$. 
silicotitanate (CST). When a waste solution contacts the ion-exchange medium, ions with low affinity are exchanged for ions with high affinity (16). Vitrification of the CST is usually performed using a low-temperature grouting process (17). However, because of the extremely low maximum level of cesium in the possible Vortec waste streams, no ion-exchange procedure is expected. Thermochemical calculations of the vaporization of the cesium in the presence of water vapor, fluorine, chlorine, and chromium were performed to determine which phases would form and approximately at what temperature the cesium components would condense within the Vortec system.

The different cesium-containing species included in the FACT database are listed in Table 4. Figure 18 illustrates the maximum concentrations of cesium-derived components in the vapor as functions of temperature for oxygen-to-propane ratios of 4.00 (reducing) and 5.44 (oxidizing). As expected from the literature survey, all of the cesium vaporizes in the flame. The major vapor phases predicted under oxidizing conditions are $\mathrm{Cs}_{2} \mathrm{CrO}_{4}, \mathrm{CsOH}, \mathrm{CsF}$, and $\mathrm{CsCl}$, while under reducing conditions, cesium metal becomes a significant component. At approximately $1500^{\circ} \mathrm{F}$, the cesium begins condensing from the gas under the oxidizing conditions, while under reducing conditions, the condensation does not begin until the temperatures drops to approximately $1200^{\circ} \mathrm{F}$. As shown in Figure 19, the condensation temperatures increase by approximately $100^{\circ} \mathrm{F}$ for every order of magnitude increase in the concentration of cesium in the feedstock. The major condensed phase is $\mathrm{Cs}_{2} \mathrm{Cr}_{2} \mathrm{O}_{7}$ liquid. The material would be expected to begin condensing near the back end of the heat recuperator, either on system surfaces or on entrained particulates or homogeneously as submicron entrained particulates. However, the concentrations in the vapor would be extremely low; less than a tenth of a part per quadrillion is the most expected based on the maximum level of cesium in the Vortec feedstock expected for the initial 30-day test.

\subsection{CONCLUSIONS}

The thermochemical equilibrium calculations indicate that at the temperature of a propane-air flame, some volatilization of uranium, plutonium, technetium, and cesium will occur. The expected concentrations of plutonium, technetium, and cesium in the flame will be very low because of the small maximum concentration of these elements in the projected feed materials for the first 30-day test. The quantities volatilized can generally be decreased by operating the flame in a fuel-rich mode, although this will lead to greater carbon monoxide production, which may be more objectionable. The concentrations of chlorine and fluorine, at least at the maximum levels in the projected Vortec feed, are not projected to greatly influence the vaporization rates. Therefore, blending to reduce the concentrations of those elements would most likely not be effective in reducing metal vaporization. Most of the elements vaporized condense by the time the gas cools to $2000^{\circ} \mathrm{F}$. These elements would condense either on surfaces near the front of the heat recuperator or on entrained particulates or homogeneously as relatively pure submicron particles. Cesium would be expected to condense at the lower temperatures near the rear of the recuperator, although the expected maximum concentration in the Vortec feed material is extremely low so it should be greatly diluted by other particulates. The elements that condense on other entrained particles will form enriched surface coatings. Particles larger than 

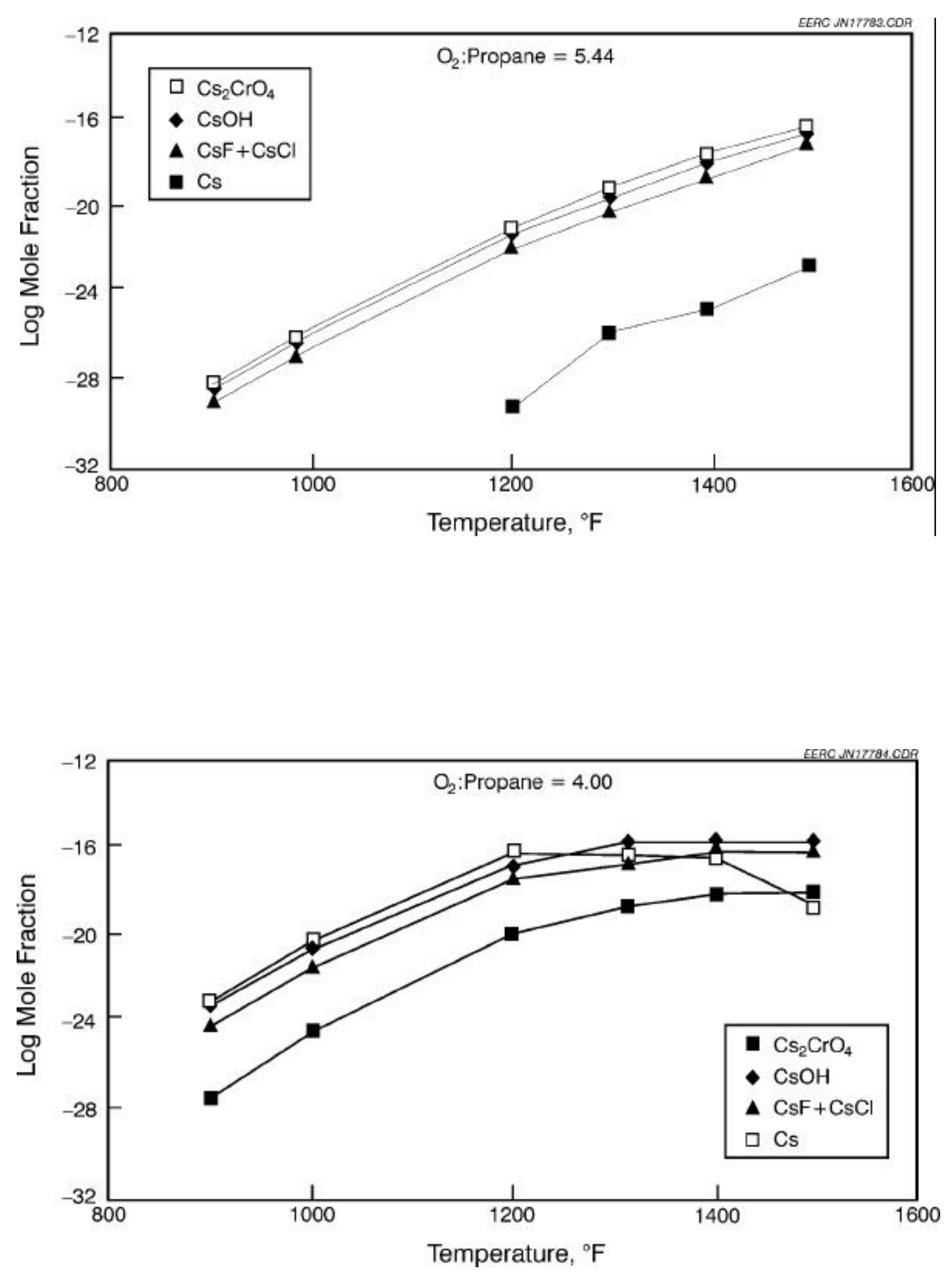

Figure 18. Concentrations of different vapor-phase cesium species as functions of temperature for oxygen-to-propane ratios of 4.00 (reducing) and 5.44 (oxidizing). 


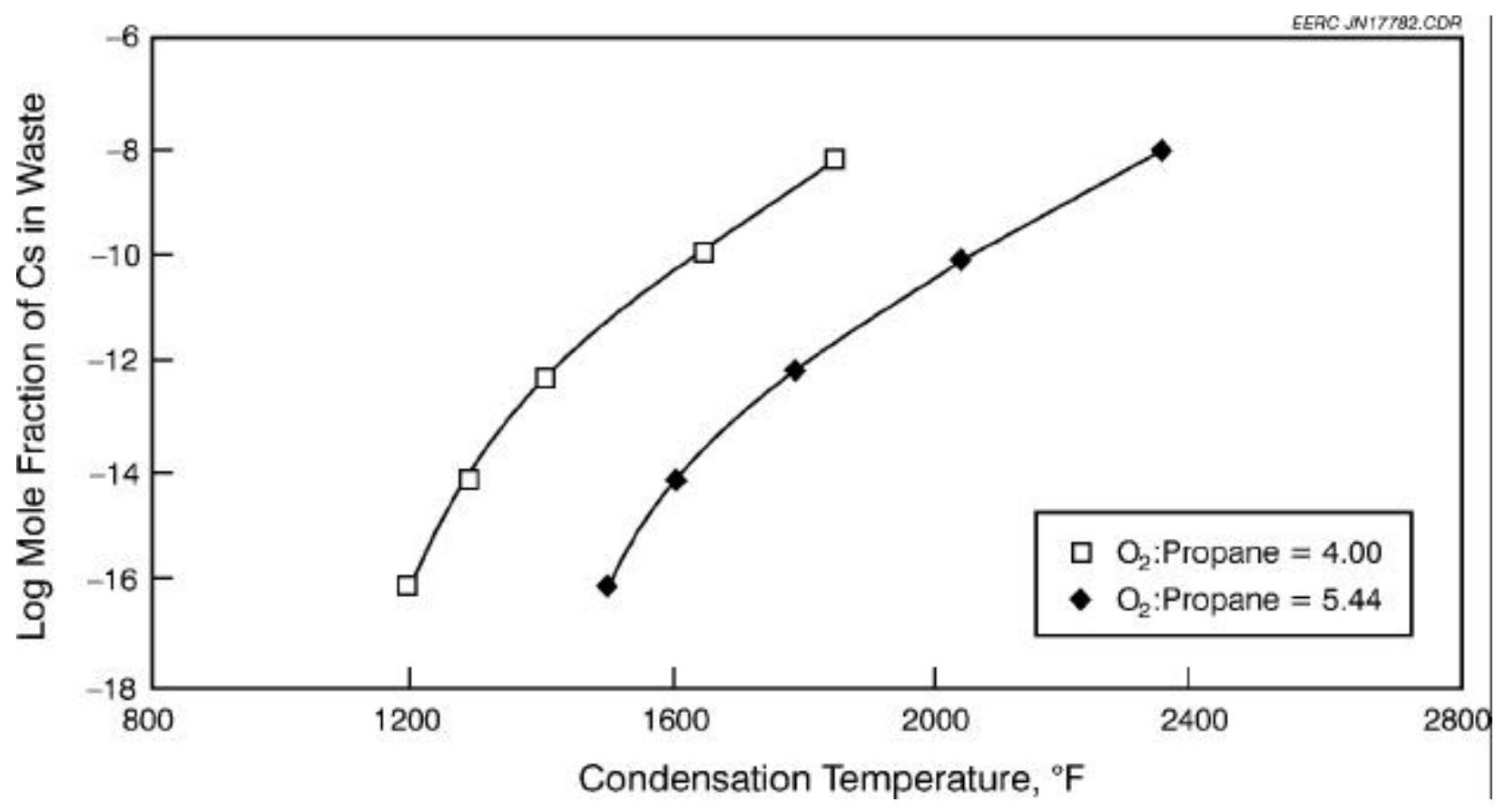

Figure 19. Condensation temperature of $\mathrm{Cs}_{2} \mathrm{CrO}_{4}$ liquid as a function of temperature and concentration for reducing and oxidizing conditions.

$10 \mu \mathrm{m}$ or so will be collected in the scrubber. Smaller particles, especially the submicron particles formed from homogeneous nucleation, should be largely collected in the HEPA filter.

Deposits formed in the heat recuperator can normally be handled via sootblowing. To reduce handling problems, we suggest that the recuperator be oriented vertically so that the deposits blown off of the heat exchanger fall directly into the molten glass. The large size of the deposits should help to reduce the rate of revaporization, allowing the volatile elements to be removed with the glass. The volatile elements that do not deposit on system surfaces will be concentrated in the smaller particles. Therefore the HEPA ash will be greatly enriched in these elements. If the HEPA filter is itself sent to a melter, the elements may revaporize and multiply the problems related to metal vaporization significantly. Therefore, the HEPA filters should be disposed of without high-temperature processing. Also, to reduce the formation of these very small particles, it is helpful to include larger particles in the feed to act as condensation nuclei that can then be collected in the scrubber. This can be accomplished by using feed materials with a fraction consisting of particles small enough that they will not be collected in the cyclone in the melter, but large enough so that they will easily be collected by the scrubber. This is one advantage that firing bituminous coal has over gas firing; it provides a source of ash particles of the right size range to serve as nucleation sites, but large enough (depending on the coal) so that they can usually be collected efficiently in the scrubber system. 


\subsection{REFERENCES}

1. Radioactive Waste Forms for the Future; Lutze, W.; Ewing, R.C.; Eds.; North Holland, Amsterdam, 1988.

2. Wang, E; Kuang, H.; Matlack, K.S.; Buechele, A.C.; Fu, S. Effect of Fluoride on Crystallization in High Calcium and Magnesium Glasses. Mat. Res. Soc. Symp. Proc. 1994, $333,473$.

3. Jantzen, C.M.; Plodinec M.J. Thermodynamic Model of Natural Medieval and Nuclear Waste Glass Durability. J. Non-Cryst. Solids 1984, 67201

4. Bickford, D.F.; Applewhite-Ramsey, A.; Jantzen, C.M.; Brown K.G. Control of Radioactive Waste Glass Melters: 1. Preliminary General Limits at Savannah River. J. Am. Ceram. Soc. 1990, 73, 2896.

5. Zhou, W.; Chambre, P.L.; Pigford, T.H.; Lee, W.W.-L. Analysis of Evaporation in Nuclear Waste Boreholes in Unsaturated Tuff. Mat. Res. Soc. Symp. Proc. 1992, 294, 3439.

6. Sunder, S.; Cramer, J.J.; Miller, N.H. X-Ray Photoelectron Spectroscopic Study of Cigar Lake Uranium Ore: a Natural Analog for Used Fuel. Mat. Res. Soc. Symp. Proc. 1992, 257, 449.

7. Janeczek, A.; Ewing, R.C. Coffinization - a Mechanism for the Alteration of $\mathrm{UO}_{2}$ Under Reducing Conditions. Mat. Res. Soc. Symp. Proc. 1992, 257, 497.

8. Brown, G.E., Jr.; Farges, F.; Calas, G. X-Ray Scattering and X-Ray Spectroscopy Studies of Silicate Melts. Reviews in Mineralogy 1995, 32, 317.

9. Sunder, S.; Shoesmith, D.W.; Miller, N.H. Electrochemical Studies of Corrosion of Simfuel: Simulated used $\mathrm{UO}_{2}$ Fuel. Mat. Res. Soc. Symp. Proc. 1993, 294, 35.

10. Stroes-Gascoyne, S.; Tait, J.C.; Porth, R.J.; McConnell, J.L.; Barnsdale, T.R.; Watson, S. Measurements of Grain-Boundary Inventories of ${ }^{137} \mathrm{Cs},{ }^{90} \mathrm{Sr}$ and ${ }^{99} \mathrm{Tc}$ in Used Candu Fuel. Mat. Res. Soc. Symp. Proc. 1993, 294, 41.

11. Einzinger, R.E.; Thomas, L.E.; Buchanan, H.C.; Stout, R.B. J. Nucl. Mater. 1992, $190,53$.

12. Krikorian, O.H.; Fontes, A.S. Jr.; Ebbinghaus, B.B.; Adamson, M.G. Transpiration Studies on the Volatilities of $\mathrm{PuO}_{3}(\mathrm{~g})$ and $\mathrm{PuO}_{2}(\mathrm{OH}) \mathrm{g}$ from $\mathrm{PuO}_{2}(\mathrm{~s})$ in the Presence of Steam and Oxygen and Application to Plutonium Volatility in Mixed-Waste Thermal Oxidation Processors. J. Nuclear Mater. 1997, 247, 161; Proc. 1996, 9th Intern. Symp. Therm. Nuclear Materials, Aug 25-30, 1996. 
13. Migge, H. Thermochemical Comparison of the Systems Re-O and Tc-O. Mat. Res. Soc. Symp. Proc. 1989, 127, 205.

14. Freude, E.; Lutze, W.; Russel, C.; Schaeffer, A. Investigation of the Redox Behavior of Technetium in Borosilicate Glass Melts by Voltammetry. Mat. Res. Soc. Symp. Proc. 1989, 127, 199.

15. Kamizono, H.; Muraoka, S.; Time-Dependence of Volatilization of 137Cs and 106Ru over High-Level Waste Glass in a Canister. Mat. Res. Soc. Symp. Proc. 1992, 257, 191.

16. Cesium Removal Using Crystalline Silicotitanate, OST Reference \#21, Hanford Site, and Oak Ridge Reservation, Innovative Technology, Summary Report, DOE/EM-0415, 1999.

17. Vitrification of Ion Exchange Materials, OST Reference \#81, Savannah River Site, Innovative Technology, Summary Report, DOE/EM-0451, July 1999. 